See discussions, stats, and author profiles for this publication at: https://www.researchgate.net/publication/325329399

\title{
The Role of the Penultimate Foot Contact During Change of Direction: Implications on Performance and Risk of Injury
}

Article in Strength and conditioning journal · May 2018

DOl: $10.1519 /$ SSC. 0000000000000395

\section{CITATIONS}

0

4 authors:

Thomas Dos'Santos

University of Salford

46 PUBLICATIONS 114 CITATIONS

SEE PROFILE

Paul Comfort

University of Salford

158 PUBLICATIONS 1,095 CITATIONS

SEE PROFILE
1,018

Christopher Thomas

45 PUBlicATIONS 192 CITATIONS

SEE PROFILE

Paul A Jones

University of Salford

95 PUBLICATIONS 659 CITATIONS

SEE PROFILE

Some of the authors of this publication are also working on these related projects:

Project $\quad$ Exploring vertical jump performance in relation to modifiable and non-modifiable factors View project

Biomechanical Assessment of Weightlifting Derivatives View project 
The Role of the Penultimate Foot Contact During Change of Direction: Implications on Performance and Risk of Injury

Review article

Thomas Dos'Santos ${ }^{1}$, Christopher Thomas ${ }^{1,2}$, Paul Comfort ${ }^{1}$ and Paul Jones ${ }^{1}$

${ }^{1}$ Human Performance Laboratory, Directorate of Sport, Exercise, and Physiotherapy, University of Salford, Greater Manchester, United Kingdom

${ }^{2}$ School of Health, Sport and Professional Practice, University of South Wales, Pontypridd, Wales, UK

\#Corresponding Author: Thomas Dos'Santos

Telephone: +447961744517

Email: t.dossantos@edu.salford.ac.uk

Thomas Dos'Santos is a $\mathrm{PhD}$ student in Biomechanics and Strength and Conditioning at the University of Salford, UK.

Christopher Thomas is a Lecturer in Strength and Conditioning at the University of South Wales, UK.

Paul Comfort is a Senior Lecturer and program leader of the MSc Strength and Conditioning at the University of Salford, UK.

Paul A. Jones is a Lecturer in Biomechanics and Strength and Conditioning at the University of Salford, UK.

Abstract word count: 100 words

Manuscript word count: 4463 words

Number of tables and figures: 3 Tables, 5 Figures 


\section{Abstract}

Most change of direction biomechanical investigations and current technique guidelines focus on the role of the final foot contact (plant foot contact). However, it is evident that the braking characteristics during the penultimate foot contact play an integral role in deceleration prior to directional changes $\geq 60^{\circ}$; and can therefore, be described as a "preparatory step". In this review, we examine the role of the penultimate foot contact on change of direction performance and associated biomechanical injury risk factors, and provide technical guidelines for coaching the "preparatory step" during change of direction, to enhance performance and reduce risk of injury. A VIDEO ABSTRACT DESCRIBING THIS ARTICLE CAN BE FOUND IN SUPPLEMENTAL DIGITAL CONTENT 1 (SEE VIDEO, HTTP://

\section{LINKS.LWW.COM/SCJ/A240)}

Key words: cutting; turning; deceleration; braking; anterior-cruciate ligament; knee abduction moments

\section{INTRODUCTION}

The ability to change direction is an integral component of multidirectional sport, such as evading an opponent or reacting to a ball $(5,70,72,85,86,92)$. However, directional changes are also a key action associated with non-contact anterior cruciate ligament (ACL) injuries $(6,7,10,18,46,59,64,91)$, which have devastating health $(27,52)$, psychological $(27,49)$ and economic $(12,27)$ implications for athletes. Therefore, understanding the biomechanical risk factors and mechanical determinants of faster change of direction (COD) performance are of great interest to practitioners.

Most COD biomechanical investigations have generally explored the kinetic, kinematic and technical determinants of the plant limb (final foot contact or push-off limb phase) from both performance and risk of injury perspectives $(14,15,34,47,56,58,77-79,81,82)$. Additionally, COD guidelines also predominantly emphasize and provide technical and coaching guidelines for the plant phase (final foot contact) of directional changes $(24,33,35$, 63, 96). However, changing direction can be described as a multi-step action, whereby preliminary deceleration occurs over several steps, to reduce momentum, especially when running at high speeds and executing extreme angled directional changes (1). Patla et al. (67, 
68) states that directional changes must be planned and initiated in the step before the turn to facilitate effective COD performance. This is substantiated by previous studies that have reported athletes make anticipatory postural adjustments (APA) in the step prior to (penultimate foot contact (PFC)) the COD (final foot contact (FFC)), demonstrating kinematic changes in foot placement, trunk lean and rotation, and head rotation $(37,51,60$, 69, 93, 95). Furthermore, braking characteristics such as greater braking forces and external knee flexor moments (KFM) have been reported in the step prior (PFC) to CODs $\geq 60^{\circ}$ (20, 25, 42-45), highlighting the importance of the PFC during extreme directional changes.

The findings of previous research have shown soccer players perform $\sim 100$ CODs of 90-180 during a soccer match (5), while Robinson et al. (70) reported $\sim 80$ CODs of $45-135^{\circ}$ and $\sim 20$ turns $\geq 135^{\circ}$ in soccer matches from a minimum approach velocity of $4 \mathrm{~m} . \mathrm{s}^{-1}$. Furthermore, Sweeting et al. (85) recently reported that $90^{\circ}$ and $180^{\circ}$ turns are frequently performed movements in netball, and the $180^{\circ}$ turn is a fundamental movement for cricket batsmen whereby approximately 40 turns will be performed when scoring 100 runs during a match (17). As such, the aforementioned studies highlight the importance of extreme CODs in sport. For cuts and turns $\geq 60^{\circ}$ there would be a requirement to reduce the velocity into the COD, thus momentum $(22,23,25,40)$, and as such, the preceding footfalls would be effective for deceleration prior to changing direction $(1,16,20,25,40,42-45,62,71)$. To execute extreme CODs changes efficiently, a multi-step strategy will undoubtedly be adopted by athletes (1, $16,20,25,40,42-45,62,71)$. Surprisingly, a limited number of investigations have inspected the PFC when examining COD biomechanics from both performance $(16,20,40)$ and risk of injury perspectives $(21,42-45)$, and to our knowledge, no clear coaching and technical guidelines for the PFC when changing direction exist. Analysis into the braking characteristics can provide greater understanding into the optimal braking strategies which could mitigate risk of knee injury during the FFC, where ACL injuries occur $(6,7,10,18,46$, $59,64,91)$, but also provide insight into deceleration strategies effective for COD performance $(16,20,40)$.

The aim of this review is to examine the role of the PFC when changing direction, outlining the critical characteristics associated with the deceleration phase, while considering the implications on performance and risk of injury. In addition, to assist strength and conditioning coaches in their understanding of how to coach and condition their athletes for 
better COD ability, technical and coaching guidelines for preliminary deceleration during the PFC are also provided, with recommendations of how to integrate braking strategy training into a holistic training program.

For the purpose of this review the PFC is defined as "the 2nd last foot contact with the ground prior to moving into a new intended direction" $(16,42-44)$ and is synonymous with studies which have described the PFC as the "support foot" (51), "pre COD phase" (93), "approach step" (25), "pre turn step" (62), “one step before" (60) and "before step" (45). Furthermore, FFC is defined as "the phase during a cut or pivot when an individual makes contact with the ground and initiates movement into a different direction" $(16,42-44)$ and is synonymous with studies which have described the FFC as the "push-off foot" (51), "COD phase" (93), "execution step" (25), "pivot step" (62) “cutting step" (45) and plant foot/phase $(81,82)$. Additionally, CODs between angles $0-45^{\circ}, 45-90^{\circ}$ and $>90^{\circ}$ are referred to as acute, moderate and extreme.

\section{Role of preliminary deceleration for COD: kinetic and kinematic differences between the PFC and FFC}

A summary of research that has compared PFC and FFC biomechanics during COD is presented in Table 1. Nedergaard et al. (62) used accelerometers and three-dimensional (3D) motion analysis to compare the mechanics during the FFC with those during the preceding footfalls (PFC and ipsilateral). The authors observed greater trunk decelerations and peak joint flexion velocities in the preceding two footfalls compared to the FFC during a $135^{\circ}$ ' $\mathrm{v}$ ' cut, highlighting the importance of preliminary deceleration prior to the COD. This finding substantiates Andrews et al. (1) qualitative assessment of cutting stating preliminary deceleration of several steps is key prior to executing a COD. Additionally, Rovan et al. (71) also highlighted the importance of the two steps prior to the FFC during a range of angled directional changes $\left(30^{\circ}, 60^{\circ}, 90^{\circ}, 120^{\circ}, 150^{\circ}\right.$ and $\left.180^{\circ}\right)$. Based on GPS and high-speed video analysis data the authors reported soccer players start changing direction prior to the FFC, particularly during the PFC, to facilitate the COD. Furthermore, Hader et al. $(22,23)$ recently showed that reductions in velocity are present, particularly when performing grater angled CODs reporting deceleration distances of $4.3 \pm 1.9$ and $7.1 \pm 1.2 \mathrm{~m}$ prior to executing $45^{\circ}$ and $90^{\circ}$ cuts, from a $10 \mathrm{~m}$ approach, respectively. Collectively, these results indicate the preceding footfalls are undoubtedly required for effective deceleration prior to the COD. 
However, a limitation of the abovementioned studies is only the kinematics of the preceding footfalls were established with no kinetic information regarding the joint moments or braking forces.

Havens and Sigward (25) investigated the PFC and FFC ground reaction force (GRF) properties and ground contact times (GCT) during a $45^{\circ}$ and $90^{\circ}$ cut, reporting significantly greater $(\mathrm{p}<0.001)$ posterior braking force and posterior ground reaction impulse $(G R I)$ in the PFC compared to the FFC for the $90^{\circ}$ cut only. No differences in GRI in both contacts during the $45^{\circ}$ cut were reported (25), suggesting the braking demands were evenly spread across both footfalls. Conversely, a disproportionately greater braking force and impulse was required in the PFC compared to the FFC for the $90^{\circ}$ cut, emphasizing the importance of the posterior braking force and impulse in the PFC for extreme cuts (29). These findings are supported by recent studies that have also reported significantly greater PFC braking forces during $60^{\circ}$ cuts $(45), 90^{\circ}$ cuts $(42,43)$ and $180^{\circ}$ turns $(20,42,44)$ compared to FFC. This could be attributed to CODs $>45^{\circ}$ requiring greater reductions in velocity and momentum $(22,23,25)$, thus earlier braking is required to allow effective redirected propulsion force and impulse during the FFC into the new intended direction. Furthermore, higher approach velocities into CODs are also a critical factor influencing the braking characteristics associated during the PFC, as greater posterior impulse and peak external KFMs have been reported during fast $60^{\circ}$ cuts $\left(5.51 \pm 0.32\right.$ vs $\left.4.53 \pm 0.33 \mathrm{~m} . \mathrm{s}^{-1}\right)$ compared to slower cuts, respectively. Conversely, the requirements for preliminary deceleration and reductions in velocity prior to the COD for acute CODs $(23,25)$ may be minimal, and as such, maintaining velocity may be of greater importance during these tasks.

Recently, Jones et al. (42) conducted the most comprehensive biomechanical comparison between the braking characteristics of the PFC and FFC during $90^{\circ}$ cuts and $180^{\circ}$ turns. Interestingly, significantly greater horizontal braking force (HBF), horizontal braking impulse (HBI), peak hip and knee flexion angles, and peak ankle plantar flexor moments were observed in the PFC compared to FFC during $90^{\circ}$ cuts. Conversely, for $180^{\circ}$ turns, significantly greater normalised vertical braking force (VBF), HBF, peak knee flexion angles and ankle dorsi flexion angles, peak and average KFMs, and peak ankle plantar flexor moments in the PFC were demonstrated compared to the FFC. These results support GrahamSmith et al. (20) who also documented greater peak HBF, peak VBF and peak KFMs in the 
PFC during $180^{\circ}$ turns, and support the findings of previous research that reported greater knee flexion angles and range of motion in the PFC compared to FFC (21).

Notably, Jones et al. (42) described the role of the PFC as a "preparatory step" observing knee and hip flexion throughout the stance phase which is maintained from transition of PFC to FFC. This facilitates GRF absorption through a greater range of motion, most likely in the sagittal plane (depending on COD angle) and provides an optimal body position at FFC (i.e., lower center of mass and allows the FFC leg to be planted out in front of the body). This supports Andrews et al. (1) early concept of the PFC serving as a key step in the facilitation of directional changes.

\section{Role of PFC braking characteristics on associative knee injury risk factors during COD}

Although previous studies have shown promising results regarding the role of the PFC for deceleration $(21,25,45,62)$, a shortfall of these studies are they have failed to inspect the relationships between PFC kinetic and kinematic variables with associated knee injury risk factors, such as knee abduction moments (KAM) and internal rotation moments. These aforementioned moments can increase ACL strain $(53-55,75,76,94)$ and importantly, greater KAMs has been shown to be a predictor of non-contact ACL injury in adolescent female athletes (29). Jones et al. reported greater peak HBF in the PFC compared to the FFC during cutting (43) and pivoting (44) in female soccer players. However, no significant relationships were observed between the magnitude of peak HBF and KAMs, and no significant relationships between $\mathrm{HBF}$ ratio (defined as FFC braking force / PFC braking force) and KAMs for both $90^{\circ}$ cut and $180^{\circ}$ pivot performance, respectively. The authors attributed the lack of relationships to the low sample sizes of 26 and 27, respectively. Interestingly, players with greater KAMS in both studies (Table 1) had a higher HBF ratios compared to players displaying lower KAMs, highlighting the importance of producing greater magnitudes of $\mathrm{HBF}$ in the PFC, relative to the FFC.

Jones et al. $(43,44)$ considered only peak braking force-time variables which is only representative of one instance of the force-time data. Inspecting this variable only, does not provide further insight into the "braking effect" and considering variables such as average $\mathrm{HBF}$ and impulse could provide greater insight into braking characteristics during the weight acceptance phase of the PFC (i.e., impulse (force $\times$ time) $=$ change in momentum- greater 
average forces over weight acceptance would facilitate effective braking). Recently, Jones et al. (42) considered the aforementioned variables demonstrating lower KAMs during pivoting were associated with a lower average HBF ratio (Table 1), therefore, indicating a greater proportion of braking in the PFC, relative to the FFC, may reduce knee joint loading. Furthermore, PFC average $\mathrm{HBF}$ was inversely associated with $90^{\circ}$ cut KAMs (Table 1 ).

Collectively, these findings although preliminary, could have large practical applications regarding ACL injury reduction programmes, whereby a COD technique which emphasizes greater braking (magnitudes of $\mathrm{HBF}$ ) during the PFC, where the knee goes through a greater range of knee flexion $(21,42)$ and generally performed in the sagittal plane, may alleviate KAMs in the FFC (turning or cutting limb) (42-44); which is the limb that gets injured during CODs $(6,7,10,18,46,59,64,91)$. If the braking strategy is emphasized toward the final step this will increase the resultant GRF, which could increase peak knee abduction moments (42), thus risk of injury (29). Dempsey et al. (14) has documented a 36\% reduction in peak KAMs (knee valgus moments) as a result of six weeks sidestep technique modification which focused on altering foot plant distance (closer to midline) and trunk control (upright trunk), while Jones et al. (41) has also demonstrated a reduction on KAMs following a six-week technique modification intervention. Therefore, practitioners should consider integrating braking strategy technique modification training into their injury reduction programs.

\section{Role of PFC braking characteristics on COD performance}

From a performance perspective, promising results have been demonstrated regarding the braking characteristics of the PFC $(16,20,40)$ (Table 1); however, to our knowledge only three studies have conducted such analysis. Graham-Smith et al. (20) reported faster $180^{\circ}$ turning performance was associated with greater PFC and FCC peak HBFs, and greater peak HBFs were significantly related to greater external KFMs in the PFC and FFC (Table 1). Though, it is worth noting that greater peak HBFs, and peak KFMs were demonstrated in the PFC (Table 1), therefore, highlighting the importance of braking in the PFC. However, these results were only published in a low sample size $(n=12)$.

In a larger sample $(n=40)$, Dos'Santos et al. (16) reported significant relationships between PFC peak HBF and peak HBF ratio with modified 505 left performance (Table 1). Furthermore, faster athletes demonstrated greater PFC HBFs and lower HBF ratios compared 
to slower athletes (Table 1). Recently, Jones et al. (40) reported stronger female soccer players (eccentric knee extensor peak torque) demonstrated faster 505 performance, greater approach velocities and greater reductions in velocity during the PFC in comparison to weaker subjects (Table 1). Notably, the stronger athletes produced greater PFC peak and average horizontal GRFs, and greater PFC external hip flexor moments (HFM) compared to weaker subjects (Table 1). Therefore, these results indicate that eccentrically stronger athletes possessed a greater capacity to tolerate the higher approach velocities during the COD (82). Moreover, their ability to produce greater horizontal braking forces and HFMs over the PFC, enabled greater reductions in velocity, which subsequently facilitated faster COD performance.

Collectively, the results of the abovementioned research suggest that greater magnitudes of $\mathrm{HBF}$ (peak and average) during the $\mathrm{PFC}$, relative to the $\mathrm{FFC}$, is advantageous for $180^{\circ} \mathrm{COD}$ performance; highlighting the PFC and steps prior to directional changes are important in the interaction between strength, speed and COD technique. Furthermore, from a performance perspective, braking earlier should reduce the horizontal momentum of the centre of mass $(\mathrm{COM})$ to allow more effective weight acceptance and preparation for the drive-off phase of directional changes $(16,36,40,43)$. However, the abovementioned studies are only representative of $180^{\circ}$ tasks and as the biomechanical demands are angle dependent $(3,11$, $22,23,25,26,73,74,77)$, evaluations of the PFC braking characteristics of different angled cuts and turns from a performance perspective warrant further investigation.

*** Insert Table 1 about here***

\section{Effect of anticipation on PFC COD biomechanics}

There is a paucity of research which has inspected the PFC during unplanned CODs, and these studies are mostly limited to sidesteps $\leq 45^{\circ}(51,60,93)$, with only one study investigating extreme CODs $\left(90^{\circ}\right.$ and $180^{\circ}$ ) (39). Mornieux et al. (60) examined the PFC during a pre-planned and unplanned $45^{\circ}$ sidestep (light signal produced 850, 600 and $500 \mathrm{~ms}$ prior to COD) observing significantly less head rotation towards the direction of travel and greater rotation of the trunk to the opposite direction, in comparison to pre-planned and 850 ms unanticipated conditions. Moreover, a trend in less medial placement of the PFC was also documented during the unplanned conditions (600 and $500 \mathrm{~ms}$ ). Similarly, Lee et al. (51) and 
Wheeler et al. (93) reported a medial placement of the PFC (across pelvic midline) resembling a cross over cut (XOC) (Figure 1) during pre-planned sidesteps, which helps facilitate the directional change due to effective alignment into the intended direction of travel. This contrasts to the different lateral foot placement position (laterally from pelvic midline - not resembling XOC) during unplanned sidesteps with increased temporal constraints (Figure 1). Consequently, practitioners and coaches should acknowledge these technical differences (i.e. head and trunk rotation, and PFC foot placement) when coaching and screening pre-planned and unplanned sidesteps (Figure 1).

*** Insert Figure 1 about here***

It is worth noting, that the abovementioned studies have not considered the braking characteristics (GRF and joint moments) of the PFC during a $45^{\circ}$ sidestep. However, as Havens and Sigward (25) reported minimal differences in braking forces between straight run and $45^{\circ}$ cuts (25), and the finding that minimum speed during a $45^{\circ} \mathrm{COD}$ is a determinant of faster performance (23); there may be a limited role for braking during PFC and preliminary deceleration for $45^{\circ}$ cuts, compared to extreme CODs. Interestingly, Jones et al. (39) is the only study to our knowledge comparing braking characteristics between pre-planned and unplanned (light stimulus) COD tasks, reporting less braking takes place during the PFC of unplanned $90^{\circ}$ cuts and $180^{\circ}$ turns, compared to pre-planned. This opens a potential avenue for future research regarding improving the ability to anticipate and thus, make better postural adjustments prior to FFC to lower hazardous loading patterns during the FFC. Further research is necessary to investigate the role of the PFC during unplanned conditions; specifically, utilizing a sports-specific stimulus, as the type of stimuli can also influence COD biomechanics (50).

\section{PRACTICAL APPLICATIONS: PENULTIMATE FOOT CONTACT COACHING AND TECHNICAL GUIDELINES}

Athletes should make whole-body postural adjustments in order to execute moderate and extreme directional changes safely and efficiently (1, 37, 42, 50, 51, 60, 67-69, 93, 95). Technical factors such as foot placement, adjustment of steps, and body lean and posture have been identified as determinants of COD ability (96-98). Thus, it is imperative that athletes adopt technically efficient whole-body postures over the PFC (preparatory step) and 
potentially the steps before the PFC to facilitate effective COD (subject to angle and entry velocity). However, in order to execute efficient braking strategies, athletes should possess high levels of eccentric strength to tolerate the forces associated during the braking phase (13, 38, 40, 83, 88). Technical and coaching guidelines are presented in Table 2 for the PFC during extreme cuts and turns based on the findings and suggestions of previous research, and biomechanical principles $(31,32,37,40,42-44,60,67,87)$.

***Insert Table 2 about here***

\section{Preparatory step guidelines for sharp angled cuts}

Briefly, technical characteristics for braking during PFC (Table 2) involve creating a large $\mathrm{COM}$ to center of pressure (COP) distance, via anterior placement of the PFC in front of the body, and a backward lean of the trunk to shift the COM posteriorly. This emphasizes a posteriorly directed force vector, and maximises $\mathrm{HBF}$ to reduce momentum (impulse = change in momentum) prior to the push-off phase (32, 40, 42-44). Simultaneous, hip, knee (up to $\sim 100^{\circ}$ ) and ankle dorsi-flexion occurs, in order to absorb the loading in the sagittal plane (facilitates longer braking force application, thus impulse), and lower the COM for better stability $(32,42,87)$. This occurs over a GCT of $0.15-0.40 \mathrm{~s}$ (influenced by entry velocity and angle of COD) $(16,25,45,62)$. Practitioners should be aware of knee alignment during the PFC when screening and coaching COD technique (Figure 2). The head and trunk should be directed forward, or some athletes may choose to rotate slightly towards the intended direction of travel $(37,60,67)$ for effective realignment into the new intended direction, and earlier visual scanning of the situation (31).

\section{Preparatory step guidelines for pivots}

To minimise injury risk whole body deceleration should be performed in the sagittal plane $(44,57)$; however, for directional changes to be performed as fast as possible, athletes may decide to pre-rotate (their whole body) in the transverse plane during the PFC. If this is performed, then the coaching principles outlined for cutting should be predominantly followed (Table 2), such as the emphasis on backward trunk lean, a large COM to COP distances to encourage a posteriorly directed force vector for braking and reducing the velocity of COM, and exhibition of ankle (dorsi), knee and hip flexion. However, for $180^{\circ}$ turns, athletes may perform the preparatory step in an externally rotated (transverse) position; 
though, still emphasizing a posteriorly directed force vector due to foot placement in front of the COM and backwards trunk lean (Figure 3a). If this strategy is adopted, it is imperative not to evoke knee valgus. By performing this movement in a rotated position, this may facilitate faster performance due to effective realignment into the new intended direction (26, 77).

\section{Braking strategy variance}

Practitioners should acknowledge the variance in braking strategies adopted by athletes. For example, Figure 5A illustrates an athlete demonstrating a bilateral braking strategy during a $180^{\circ}$ turn, whereby the foot involved with PFC remains in contact with the ground during the braking phase of the FFC. This technique facilitates and distributes the loading across twofoot contacts, thus maximising braking impulse over the PFC due to the longer GCT, and potentially lowering forces during the FFC. Conyersely, illustrated in Figure 5B, athletes may adopt a clear flight phase between the PFC and FFC during a $180^{\circ}$ turn, whereby the athlete will rotate their whole body during this flight phase in order to align themselves into the intended direction.

***Insert Figure 3 about here***

Different cutting strategies have been previously reported (knee, hip or ankle dominant) in male athletes (19), while females high school athletes are found to display different biomechanical deficits (quadricep, ligament, trunk and leg dominance) (66). In this review we have qualitatively identified two different $180^{\circ}$ turning strategies (Figure 3); turning strategy A may be safer from an injury reduction perspective due to the capacity to distribute loading across two-foot contacts. From a performance perspective both techniques may be equally effective; however, further research is required quantitatively comparing the aforementioned turning strategies. Although, it should be noted that certain whole-body postures may induce greater 'injury risk', but may be optimal for performance, thus practitioners should acknowledge the 'performance-injury' conflict when coaching and screening COD. Additionally, it should be noted that the deceleration requirements will be dictated by the angle and entry velocity into the COD, thus, deceleration maybe accomplished over several steps, so the steps prior to the PFC will also be important $(22,23$, 
62). Therefore, the coaching guidelines presented in Table 2 for the PFC should also be applied when coaching deceleration during several steps.

\section{Preparatory step for angled runs and lateral shuffle}

The technical guidelines for the preparatory step are based on CODs from a straight approach (Table 2); however, athletes perform directional changes from angled and oblique runs (92), while lateral shuffles are also common actions in sports such as basketball and soccer $(5,86)$. We hypothesize the PFC plays an important role, serving as a "preparatory step" with slight differences in foot placement during such conditions. For example, performing a cut from an angled or oblique run the PFC may cross anteriorly and medially across the midline of the pelvis with the trunk positioned in the intended direction of travel (Figure 4). This aids deceleration by creating a posteriorly and medially directed GRF vector to reduce the momentum into the direction change. Subsequently, this will facilitate an optimal position for weight acceptance and push-off during the FFC. Similarly, when changing direction from a lateral shuffle, the PFC should be placed medially across the pelvic midline with trunk lean into the intended direction of travel to create a force vector in the frontal plane (Figure 4). This will help reduce the velocity of athlete via an appropriately directed braking force and suitable position for FFC.

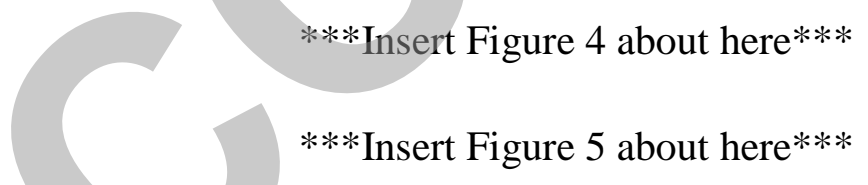

\section{PRACTICAL APPLICATIONS: TRAINING STRATEGY IMPLEMENTATION INTO THE WIDER TRAINING PROGRAM}

In order to modify COD braking strategies of athletes, practitioners are recommended to perform two 15-30-minute COD technique sessions a week, with minimum 48 hours rest between sessions (following the abovementioned technical guidelines - coaching and teaching athletes to emphasize greater braking in the PFC relative to FFC, correct lower limb alignment, whole-body posture). Dempsey et al. (14) showed a $36 \%$ reduction in KAMs as a result of six weeks sidestep technique modification. Jones et al. (41) also noted a reduction in KAMs and improvements in $180^{\circ} \mathrm{COD}$ performance in female netballers due to a six-week technique COD modification intervention. Consequently, an example six-week braking 
strategy modification intervention is presented in Table 3, beginning with pre-planned low intensity decelerations and turns (weeks 1-2), before progressing intensity via velocity (45, 90) and angle (weeks 3-4), and introducing a stimulus with increased intensity (weeks 3-6). The example program is in accordance with NSCA COD recommendations (24), previous COD speed $(8,9)$ and COD technique interventions $(14,41)$. Although, it is worth noting that for training interventions to be a success, it is integral there is "buy in" from the coach and athletes (89), and high compliance $(2,27,61,65)$. Furthermore, appropriate feedback (biomechanical or video feedback to the athlete) between reps is also central to the success of training intervention $(2,27,61,65)$, with an external focus of attention recommended for improved retention (2).

\section{*** Insert Table 3 about here*}

If practitioners and athletes have time constraints and cannot perform COD sessions, an alternative approach is to integrate braking strategy technique drills into the warm ups (neuromuscular training) of field and court based tactical/technical sessions to reduce biomechanical risk factors associated with injury (4, 48, 61, 80). Although, it should be noted, that a comprehensive training program which includes strength, plyometric (jump landing), speed, core and balance training, in addition to COD technique training may improve athletic performance and reduce risk of non-contact ACL injuries to a greater extent, than solely performing one training modality $(4,27,28,30,65,84)$. Therefore, practitioners are recommended to integrate the aforementioned training modalities into a holistic training program to optimally prepare, and enhance multidirectional athletes' COD performance and reduce risk of injury.

\section{CONCLUSIONS}

It is evident that the PFC plays an important role in deceleration when changing direction, and can therefore, be considered as a "preparatory step". Braking strategies which emphasize greater magnitudes of HBFs in the PFC, relative to the FFC, could reduce knee joint loading in the FFC, and facilitate faster performance (16, 40, 42-44). Thus, the role of the PFC should not be underestimated and overlooked when coaching and screening COD technique. Consequently, practitioners are encouraged to consider the role of the PFC during directional 
changes, and coach the "preparatory step" using the suggested technical guidelines outlined in this article when coaching COD technique.

Conflicts of Interest and Source of Funding: The authors report no conflicts of interest and no source of funding.

Figure 1. Differences in PFC placement relative to pelvic midline during unplanned and pre-planned $45^{\circ}$ sidesteps. (Unplanned left image; pre-planned right image)

Figure 2. Athlete on the left demonstrating no knee valgus during PFC performed in the sagittal plane. Athlete on the right demonstrating knee valgus during PFC.

Figure 3. Illustration of braking strategy variance during $180^{\circ}$ turns. Image A illustrates a bilateral braking strategy. Image B illustrates a clear flight phase and whole-body rotation between PFC and FFC (blue line represents force vector).

Figure 4. Role of the PFC during a cut from an angled approach sprint.

Figure 5. Role of the PFC during a lateral shuffle.

\section{REFERENCES}

1. Andrews JR, McLeod WD, Ward T, and Howard K. The cutting mechanism. Am J Sport Med 5: 111-121, 1977.

2. Benjaminse A, Gokeler A, Dowling AV, Faigenbaum A, Ford KR, Hewett TE, Onate JA, Otten B, and Myer GD. Optimization of the anterior cruciate ligament injury prevention paradigm: novel feedback techniques to enhance motor learning and reduce injury risk. J Orthop Sport Phys 45: 170182, 2015.

3. Besier TF, Lloyd DG, Cochrane JL, and Ackland TR. External loading of the knee joint during running and cutting maneuvers. Med Sci Sports Exerc 33: 1168-1175, 2001.

4. Bien DP. Rationale and implementation of anterior cruciate ligament injury prevention warm-up programs in female athletes. J Strength Cond Res 25: 271-285, 2011.

5. Bloomfield J, Polman R, and Donoghue P. Physical demands of different positions in FA Premier League soccer. J Sport Sci Med 6: 63-70, 2007.

6. Boden BP, Dean GS, Feagin JA, and Garrett WE. Mechanisms of anterior cruciate ligament injury. Orthopedics 23: 573-578, 2000.

7. Brophy RH, Stepan JG, Silvers HJ, and Mandelbaum BR. Defending puts the anterior cruciate ligament at risk during soccer: a gender-based analysis. Sports health 7: 244-249, 2015.

8. Chaalali A, Rouissi M, Chtara M, Owen A, Bragazzi N, Moalla W, Chaouachi A, Amri M, and Chamari K. Agility training in young elite soccer players: promising results compared to change of direction drills. Biol Sport 33, 2016. 
9. Chaouachi A, Chtara M, Hammami R, Chtara H, Turki O, and Castagna C. Multidirectional sprints and small-sided games training effect on agility and change of direction abilities in youth soccer. J Strength Cond Res 28: 3121-3127, 2014.

10. Cochrane JL, Lloyd DG, Buttfield A, Seward H, and McGivern J. Characteristics of anterior cruciate ligament injuries in Australian football. J Sci Med Sport 10: 96-104, 2007.

11. Cortes N, Onate J, and Van Lunen B. Pivot task increases knee frontal plane loading compared with sidestep and drop-jump. J Sports Sci 29: 83-92, 2011.

12. Cumps E, Verhagen E, Annemans L, and Meeusen R. Injury rate and socioeconomic costs resulting from sports injuries in Flanders: data derived from sports insurance statistics 2003. . Br J Sports Med 42: 767-772, 2008.

13. de Hoyo M, Sañudo B, Carrasco L, Mateo-Cortes J, Domínguez-Cobo S, Fernandes O, Del Ojo $\mathrm{JJ}$, and Gonzalo-Skok O. Effects of 10-week eccentric overload training on kinetic parameters during change of direction in football players. J Sports Sci 34: 1380-1387, 2016.

14. Dempsey AR, Lloyd DG, Elliott BC, Steele JR, and Munro BJ. Changing sidestep cutting technique reduces knee valgus loading. Am J Sport Med 37: 2194-2200, 2009.

15. Dempsey AR, Lloyd DG, Elliott BC, Steele JR, Munro BJ, and Russo KA. The effect of technique change on knee loads during sidestep cutting. Med Sci Sports Exerc 39: 1765-1773, 2007.

16. Dos'Santos T, Thomas C, Jones AP, and Comfort P. Mechanical determinants of faster change of direction speed performance in male athletes. J Strength Cond Res 31: 696-705, 2017.

17. Duffield R and Drinkwater EJ. Time-motion analysis of test and one-day international cricket centuries. J Sports Sci 26: 457-464, 2008.

18. Faude O, Junge A, Kindermann W, and Dvorak J. Injuries in female soccer players a prospective study in the german national league. Am J Sport Med 33: 1694-1700, 2005.

19. Franklyn-Miller A, Richter C, King E, Gore S, Moran K, Strike S, and Falvey E. Athletic groin pain (part 2): a prospective cohort study on the biomechanical evaluation of change of direction identifies three clusters of movement patterns. Br J Sports Med 51: 460-468, 2017.

20. Graham-Smith P, Atkinson L, Barlow R, and Jones P. Braking characteristics and load distribution in 180 degree turns. Presented at Proceedings of the 5th annual UKSCA conference, 2009.

21. Greig M. The influence of soccer-specific activity on the kinematics of an agility sprint. Eur J Sports Sci 9: 23-33, 2009.

22. Hader K, Mendez-Villanueva A, Palazzi D, Ahmaidi S, and Buchheit M. Metabolic Power Requirement of Change of Direction Speed in Young Soccer Players: Not All Is What It Seems. PloS one 11: e0149839, 2016.

23. Hader K, Palazzi D, and Buchheit M. Change of Direction Speed in Soccer: How Much Braking is Enough? Kineziologija 47: 67-74, 2015.

24. Haff GG and Triplett NT. Essentials of Strength Training and Conditioning 4th Edition. Champaign, II, USA. Human kinetics, 2015.

25. Havens KL and Sigward SM. Whole body mechanics differ among running and cutting maneuvers in skilled athletes. Gait Posture 42: 240-245, 2014. 
26. Havens KL and Sigward SM. Joint and segmental mechanics differ between cutting maneuvers in skilled athletes. Gait Posture 41: 33-38, 2015.

27. Hewett TE. Preventive biomechanics: A paradigm shift with a translational approach to biomechanics. J Sci Med Sport 20: e67, 2017.

28. Hewett TE, Lindenfeld TN, Riccobene JV, and Noyes FR. The effect of neuromuscular training on the incidence of knee injury in female athletes. Am J Sport Med 27: 699-706, 1999.

29. Hewett TE, Myer GD, Ford KR, Heidt RS, Colosimo AJ, McLean SG, Van den Bogert AJ, Paterno MV, and Succop P. Biomechanical measures of neuromuscular control and valgus loading of the knee predict anterior cruciate ligament injury risk in female athletes a prospective study. $A m \mathrm{~J}$ Sport Med 33: 492-501, 2005.

30. Hewett TE, Stroupe AL, Nance TA, and Noyes FR. Plyometric training in female athletes: decreased impact forces and increased hamstring torques. Am J Sport Med 24: 765-773, 1996.

31. Hewit J, Cronin J, Button C, and Hume P. Understanding change of direction performance via the 90 turn and sprint test. Strength Cond J 32: 82-88, 2010.

32. Hewit J, Cronin J, Button C, and Hume P. Understanding deceleration in sport. Strength Cond J 33: 47-52, 2011.

33. Holding R and Meir R. Applying Biomechanical Research to Coaching Instruction of Stepping Movements in Rugby Football. Strength Cond J 36: 8-12, 2014.

34. Jamison ST, Pan X, and Chaudhari AMW. Knee moments during run-to-cut maneuvers are associated with lateral trunk positioning. J Biomech 45: 1881-1885, 2012.

35. Jeffreys I and Moody J. Strength and Conditioning for Sports Performance. London and New York. Routledge, 2016.

36. Jindrich DL, Besier TF, and Lloyd DG. A hypothesis for the function of braking forces during running turns. J Biomech 39: 1611-1620, 2006.

37. Jindrich DL and Qiao M. Maneuvers during legged locomotion. Chaos: An Interdisciplinary J Nonlinear Sci 19: 026105, 2009.

38. Jones P, Bampouras TM, and Marrin K. An investigation into the physical determinants of change of direction speed. J Sports Med Phys Fitness 49: 97, 2009.

39. Jones P, Stones S, and Smith L. A comparison of braking characteristics between pre-planned and unanticipated changing direction tasks in female soccer players: An exploratory study. Day 1. Posters-Biomechanics, BASES Annual Conference, 25th November 2014, St Georges Park, Burton. Journal of Sports Sciences 32: S25-S26, 2014.

40. Jones P, Thomas C, Dos'Santos T, McMahon J, and Graham-Smith P. The Role of Eccentric Strength in $180^{\circ}$ Turns in Female Soccer Players. Sports 5: 42, 2017.

41. Jones PA, Barber OR, and Smith LC. Changing pivoting technique reduces knee valgus moments. Free Communication. Journal of Sports Sciences. Presented at BASES Annual Conference, 2015.

42. Jones PA, Herrington L, and Graham-Smith P. Braking characteristics during cutting and pivoting in female soccer players. J Electromyogr Kines 30: 46-54, 2016. 
43. Jones PA, Herrington LC, and Graham-Smith P. Technique determinants of knee joint loads during cutting in female soccer players. Hum Movement Sci 42: 203-211, 2015.

44. Jones PA, Herrington LC, and Graham-Smith P. Technique determinants of knee abduction moments during pivoting in female soccer players. Clin Biomech 31: 107-112, 2016.

45. Kimura K and Sakurai S. A Sidestep Cut Preparation Strategy Decreases the External Load Applied to the Knee Joint. Int J Sport Health Sci 11: 109-117, 2013.

46. Koga H, Nakamae A, Shima Y, Iwasa J, Myklebust G, Engebretsen L, Bahr R, and Krosshaug T. Mechanisms for noncontact anterior cruciate ligament injuries knee joint kinematics in 10 injury situations from female team handball and basketball. Am J Sport Med 38: 2218-2225, 2010.

47. Kristianslund E, Faul O, Bahr R, Myklebust G, and Krosshaug T. Sidestep cutting technique and knee abduction loading: implications for ACL prevention exercises. Br J Sports Med 48: 779-783, 2014.

48. LaBella CR, Huxford MR, Grissom J, Kim K-Y, Peng J, and Christoffel KK. Effect of neuromuscular warm-up on injuries in female soccer and basketball athletes in urban public high schools: cluster randomized controlled trial. Arch Pediat Adol Med 165: 1033-1040, 2011.

49. Langford JL, Webster KE, and Feller JA. A prospective longitudinal study to assess psychological changes following anterior cruciate ligament reconstruction surgery. Br J Sports Med 43: 377-378, 2009.

50. Lee MJC, Lloyd DG, Lay BS, Bourke PD, and Alderson JA. Effects of different visual stimuli on postures and knee moments during sidestepping. Med Sci Sports Exerc 45: 1740-1748, 2013.

51. Lee MJC, Lloyd DG, Lay BS, Bourke PD, and Alderson JA. Different visual stimuli affect body reorientation strategies during sidestepping. Scand J Med Sci Spor 27: 492-500, 2017.

52. Lohmander LS, Englund PM, Dahl LL, and Roos EM. The long-term consequence of anterior cruciate ligament and meniscus injuries. Am J Sport Med 35: 1756-1769, 2007.

53. Markolf KL, Burchfield DM, Shapiro MM, Shepard MF, Finerman GAM, and Slauterbeck JL. Combined knee loading states that generate high anterior cruciate ligament forces. J Orthop Res 13: 930-935, 1995.

54. Markolf KL, Gorek JF, Kabo JM, and Shapiro MS. Direct measurement of resultant forces in the anterior cruciate ligament. An in vitro study performed with a new experimental technique. $J$ Bone Joint Surg Am 72: 557-567, 1990.

55. Markolf KL, O'Neill G, Jackson SR, and McAllister DR. Effects of applied quadriceps and hamstrings muscle loads on forces in the anterior and posterior cruciate ligaments. Am J Sport Med 32: 1144-1149, 2004.

56. Marshall BM, Franklyn-Miller AD, King EA, Moran KA, Strike S, and Falvey A. Biomechanical factors associated with time to complete a change of direction cutting maneuver. J Strength Cond Res 28: 2845-2851, 2014.

57. McLean SG, Huang X, Su A, and Van Den Bogert AJ. Sagittal plane biomechanics cannot injure the ACL during sidestep cutting. Clin Biomech 19: 828-838, 2004. 
58. McLean SG, Huang X, and van den Bogert AJ. Association between lower extremity posture at contact and peak knee valgus moment during sidestepping: implications for $\mathrm{ACL}$ injury. Clin Biomech 20: 863-870, 2005.

59. Montgomery C, Blackburn J, Withers D, Tierney G, Moran C, and Simms C. Mechanisms of $A C L$ injury in professional rugby union: a systematic video analysis of 36 cases. Br J Sports Med: bjsports-2016-096425, 2016.

60. Mornieux G, Gehring D, Fürst P, and Gollhofer A. Anticipatory postural adjustments during cutting manoeuvres in football and their consequences for knee injury risk. J Sports Sci 32: 12551262, 2014.

61. Myklebust G, Engebretsen L, BrÃ ikken IH, SkjÃ ,lberg A, Olsen O-E, and Bahr R. Prevention of anterior cruciate ligament injuries in female team handball players: a prospective intervention study over three seasons. Clin J Sport Med 13: 71-78, 2003.

62. Nedergaard NJ, Kersting $\mathrm{U}$, and Lake M. Using accelerometry to quantify deceleration during a high-intensity soccer turning manoeuvre. J Sports Sci 32: 1897-1905, 2014.

63. Nimphius S. Increasing Agility. High-Performance Training for Sports. Champaign, II, USA. Human Kinetics, 2014.

64. Olsen O-E, Myklebust G, Engebretsen L, and Bahr R. Injury mechanisms for anterior cruciate ligament injuries in team handball a systematic video analysis. Am J Sport Med 32: 1002-1012, 2004.

65. Pappas E, Nightingale EJ, Simic M, Ford KR, Hewett TE, and Myer GD. Do exercises used in injury prevention programmes modify cutting task biomechanics? A systematic review with metaanalysis. Br J Sports Med 49: 673-680, 2015.

66. Pappas E, Shiyko MP, Ford KR, Myer GD, and Hewett TE. Biomechanical Deficit Profiles Associated with ACL Injury Risk in Female Athletes. Med Sci Sports Exerc 48: 107-113, 2016.

67. Patla $A E$, Adkin $A$, and Ballard T. Online steering: coordination and control of body center of mass, head and body reorientation. Exp Br Res 129: 629-634, 1999.

68. Patla AE, Prentice SD, Robinson C, and Neufeld J. Visual control of locomotion: strategies for changing direction and for going over obstacles. J Exp Psychol Human 17: 603, 1991.

69. Qiao M, Brown B, and Jindrich DL. Compensations for increased rotational inertia during human cutting turns. J Exp Biol 217: 432-443, 2014.

70. Robinson G, O'Donoghue P, and Nielson P. Path changes and injury risk in English FA Premier League soccer. Int J Perf Anal Spor 11: 40-56, 2011.

71. Rovan K, Kugovnik O, Holmberg LJ, and Supej M. The steps needed to perform acceleration and turning at different approach speeds. Kinesiologia Slovenica 20: 38-50, 2014.

72. Sayers $M$ and Washington-King J. Characteristics of effective ball carries in Super 12 rugby. Int J Perf Anal Spor 5: 92-106, 2005.

73. Schot P, Dart J, and Schuh M. Biomechanical analysis of two change-of-direction maneuvers while running. J Orthop Sport Phys 22: 254-258, 1995.

74. Schreurs MJ, Benjaminse A, and Lemmink KA. Sharper angle, higher risk? The effect of cutting angle on knee mechanics in invasion sport athletes. J Biomech 63: 144-150, 2017. 
75. Shin CS, Chaudhari AM, and Andriacchi TP. The effect of isolated valgus moments on ACL strain during single-leg landing: a simulation study. J Biomech 42: 280-285, 2009.

76. Shin CS, Chaudhari AM, and Andriacchi TP. Valgus plus internal rotation moments increase anterior cruciate ligament strain more than either alone. Med Sci Sports Exerc 43: 1484-1491, 2011.

77. Sigward SM, Cesar GM, and Havens KL. Predictors of frontal plane knee moments during side-step cutting to 45 and 110 degrees in men and women: implications for anterior cruciate ligament injury. Clin J Sport Med 25: 529-534, 2015.

78. Sigward SM and Powers CM. The influence of gender on knee kinematics, kinetics and muscle activation patterns during side-step cutting. Clin Biomech 21: 41-48, 2006.

79. Sigward SM and Powers CM. Loading characteristics of females exhibiting excessive valgus moments during cutting. Clin Biomech 22: 827-833, 2007.

80. Soligard Tr, Myklebust G, Steffen K, Holme I, Silvers H, Bizzini M, Junge A, Dvorak J, Bahr R, and Andersen TE. Comprehensive warm-up programme to prevent injuries in young female footballers: cluster randomised controlled trial. Brit Med J 337: a2469, 2008.

81. Spiteri T, Cochrane JL, Hart NH, Haff GG, and Nimphius S. Effect of strength on plant foot kinetics and kinematics during a change of direction task. Eur J Sports Sci 13: 646-652, 2013.

82. Spiteri T, Newton RU, Binetti M, Hart NH, Sheppard JM, and Nimphius S. Mechanical determinants of faster change of direction and agility performance in female basketball athletes. $J$ Strength Cond Res 28: 2205-2214, 2015.

83. Spiteri T, Nimphius S, Hart NH, Specos C, Sheppard JM, and Newton RU. The contribution of strength characteristics to change of direction and agility performance in female basketball athletes J Strength Cond Res 28: 2415-2423, 2014.

84. Stojanovic MD and Ostojic SM. Preventing ACL injuries in team-sport athletes: a systematic review of training interventions. Res Sports Med 20: 223-238, 2012.

85. Sweeting AJ, Aughey RJ, Cormack SJ, and Morgan S. Discovering frequently recurring movement sequences in team-sport athlete spatiotemporal data. J Sports Sci 35: 2439-2445, 2017.

86. Taylor JB, Wright AA, Dischiavi SL, Townsend MA, and Marmon AR. Activity Demands During Multi-Directional Team Sports: A Systematic Review. Sports Med 47: 2533-2551, 2017.

87. Tominaga R, Ishii $Y$, Ueda $T$, and Kurokawa $T$. The effects of running speed on ground reaction forces and lower limb kinematics during single-leg stop movement. J Strength Cond Res 30: 1224-1230, 2016.

88. Tous-Fajardo J, Gonzalo-Skok O, Arjol-Serrano JL, and Tesch P. Enhancing Change-ofDirection Speed in Soccer Players by Functional Inertial Eccentric Overload and Vibration Training. Int J Sports Physiol and Perform 11: 66-73, 2015.

89. Twomey D, Finch C, Roediger E, and Lloyd DG. Preventing lower limb injuries: is the latest evidence being translated into the football field? J Sci Med Sport 12: 452-456, 2009.

90. Vanrenterghem J, Venables E, Pataky T, and Robinson MA. The effect of running speed on knee mechanical loading in females during side cutting. J Biomech 45: 2444-2449, 2012. 
91. Walden M, Krosshaug T, Bjorneboe J, Andersen TE, Faul O, and Hagglund M. Three distinct mechanisms predominate in non-contact anterior cruciate ligament injuries in male professional football players: a systematic video analysis of 39 cases. Br J Sports Med 49: 1452-1460, 2015.

92. Wheeler KW, Askew CD, and Sayers MG. Effective attacking strategies in rugby union. Eur J Sports Sci 10: 237-242, 2010.

93. Wheeler KW and Sayers MGL. Modification of agility running technique in reaction to a defender in rugby union. J Sport Sci Med 9: 445-451, 2010.

94. Withrow TJ, Huston LJ, Wojtys EM, and Ashton-Miller JA. The effect of an impulsive knee valgus moment on in vitro relative ACL strain during a simulated jump landing. Clin Biomech 21: 977983, 2006.

95. Xu D, Carlton LG, and Rosengren KS. Anticipatory postural adjustments for altering direction during walking. J Motor Behav 36: 316-326, 2004.

96. Young W and Farrow D. A review of agility: Practical applications for strength and conditioning. Strength Cond J 28: 24-29, 2006.

97. Young WB, Dawson B, and Henry GJ. Agility and change-of-direction speed are independent skills: Implications for training for agility in invasion sports. Int J Sports Sci Coa 10: 159-169, 2015.

98. Young WB, James R, and Montgomery I. Is muscle power related to running speed with changes of direction? J Sports Med Phys Fitness 42: 282-288, 2002. 
Table 1. Summary of research that has examined the role of the PFC on injury risk factors, performance and comparisons to FFC

\begin{tabular}{|c|c|c|c|c|c|}
\hline Study & $\begin{array}{c}\text { Subjects } \\
\text { (mean } \pm \text { SD; age, height } \\
\text { and mass) }\end{array}$ & $\begin{array}{l}\text { COD task (Angle, } \\
\text { velocity and pre- } \\
\text { planned/ unplanned) }\end{array}$ & $\begin{array}{l}\text { Kinetic and kinematic comparison between PFC } \\
\text { and FFC }\end{array}$ & Role of PFC on KAMs & $\begin{array}{l}\text { Role of PFC on COD performance } \\
\text { (Association with completion time) }\end{array}$ \\
\hline $\begin{array}{l}\text { Jones et al. } \\
\quad(43)\end{array}$ & $\begin{array}{c}26 \text { female soccer }(21 \pm 3.2 \text { years, } \\
1.68 \pm 0.07 \mathrm{~m}, 59.1 \pm 6.8 \mathrm{~kg})\end{array}$ & $\begin{array}{l}\text { PP } 5 \times 3 \mathrm{~m} 90^{\circ} \text { cut } \\
\text { (right foot plant) } \\
4.42 \pm 0.23 \mathrm{~m} \cdot \mathrm{s}^{-1}\end{array}$ & PFC vs FFC: $\uparrow$ peak HBF & $\begin{array}{l}\text { Subjects }(n=7) \text { with greater pKAMs }(+0.5 \mathrm{SD} \\
\text { above the mean) vs lower }(\mathrm{n}=8)(-0.5 \mathrm{SD} \text { below } \\
\text { the mean }) \\
\qquad \quad \uparrow \text { peak HBF ratio }(0.87 \pm 0.04 \text { vs } 0.82 \pm \\
\quad 0.04, \mathrm{ES}=1.25)\end{array}$ & \\
\hline $\begin{array}{l}\text { Jones et al. } \\
\text { (44) }\end{array}$ & $\begin{array}{l}27 \text { female soccer }(21 \pm 3.8 \text { years, } \\
1.67 \pm 0.07 \mathrm{~m}, 60.0 \pm 7.2 \mathrm{~kg})\end{array}$ & $\begin{array}{l}\text { PP } 5 \times 5 \mathrm{~m} 180 \text { pivot to } \\
\text { the left (right foot } \\
\text { plant) } \\
4.02 \pm 0.2 \mathrm{~m} \cdot \mathrm{s}^{-1}\end{array}$ & PFC vs FFC: $\uparrow$ peak HBF & $\begin{array}{l}\text { Subjects }(\mathrm{n}=9) \text { with greater } \mathrm{pKAMs}(+0.5 \mathrm{SD} \\
\text { above the mean) vs lower }(\mathrm{n}=9)(-0.5 \mathrm{SD} \text { below } \\
\text { the mean }) \\
-\quad \uparrow \text { peak HBF ratio }(0.99 \pm 0.24 \text { vs } 0.92 \pm\end{array}$ & \\
\hline $\begin{array}{l}\text { Jones et al. } \\
\quad(42)\end{array}$ & $\begin{array}{c}\text { Twenty-two female soccer players } \\
(21 \pm 3.1 \text { years, } 1.68 \pm 0.07 \mathrm{~m} \\
58.9 \pm 7.3 \mathrm{~kg})\end{array}$ & $\begin{array}{l}\text { PP } 5 \times 3 \mathrm{~m} 90^{\circ} \text { cut } \\
4.40 \pm 0.22 \mathrm{~m}^{-1} \\
\text { PP } 5 \times 5 \mathrm{~m} 180 \text { pivot to } \\
\text { the left (right foot } \\
\text { plant) } \\
4.03 \pm 0.20 \mathrm{~m} . \mathrm{s}^{-1}\end{array}$ & $\begin{array}{ll}\text { - } & 90^{\circ} \mathrm{CUT} \text { : PFC vs FFC: } \downarrow \text { GCT, } \uparrow \text { peak } \\
\text { HBF, HBI, peak hip and knee flexion } \\
\text { angles, peak ankle-plantar flexor moments } \\
\text { - } \quad \text { FFC vs PFC: } \uparrow \text { average VBF, average HBF } \\
\text { and greater average hip joint moment } \\
\text { - } 180^{\circ}: \text { PFC vs FFC: } \downarrow \text { GCT, } \uparrow \text { peak VBF, } \\
\text { peak HBF, ankle dorsi flexion angles, peak } \\
\text { and average knee flexor moments and peak } \\
\text { ankle plantar flexor moments } \\
\text { - } \quad \text { FFC vs PFC: } \uparrow \text { average VBF, HBF, HBI and } \\
\text { average hip joint moments during WA }\end{array}$ & $\begin{array}{l}\text { 180: Average HBF ratio }\left(r=0.466, r^{2}=22 \%, p=\right. \\
0.029) . \\
90^{\circ} \text { CUT: Average PFC HBF }\left(r=-0.569, r^{2}=\right. \\
32 \%, p=0.006) .\end{array}$ & \\
\hline $\begin{array}{l}\text { Havens \& } \\
\text { Sigward (25) }\end{array}$ & $\begin{array}{l}\text { Twenty-five healthy soccer players } \\
(12 \text { females) }(22.4 \pm 3.9 \text { years; } \\
1.74 \pm 0.1 \mathrm{~m} ; 70.9 \pm 9.3 \mathrm{~kg})\end{array}$ & $\begin{array}{l}\text { PP } 15 \mathrm{~m} \text { Trials- } 45^{\circ} \text { cut } \\
\text { after } 7.5 \mathrm{~m} 5.83 \pm 0.45 \\
\mathrm{~m} . \mathrm{s}^{-1} 90^{\circ} \text { cut after } 7.5 \mathrm{~m} \\
\quad 4.72 \pm 0.35 \mathrm{~m} \cdot \mathrm{s}^{-1}\end{array}$ & $\begin{array}{l}90^{\circ} \mathrm{CUT} \text { : PFC vs FFC: } \downarrow \text { GCT, } \uparrow \text { posterior } \\
\text { GRI and posterior GRF } \\
45^{\circ} \mathrm{CUT} \text { : PFC vs FFC: } \leftrightarrow \text { posterior braking } \\
\text { GRI and posterior GRF }\end{array}$ & & \\
\hline $\begin{array}{l}\text { Graham Smith } \\
\text { et al. (20) }\end{array}$ & $\begin{array}{l}12 \text { male sports students (football or } \\
\text { rugby) }\end{array}$ & Mod505 & $\begin{array}{l}\text { - } \mathrm{PFC} \text { vs FFC: } \uparrow \text { peak HBF, peak VBF, peak } \\
\text { knee extensor moments } \\
\text { - } \uparrow \text { HBF related to greater knee flexor } \\
\text { moments }\left(r=-0.659, p=0.02, r^{2}=43.4 \%\right)\end{array}$ & & $\begin{array}{l}\uparrow \mathrm{PFC} \text { peak } \operatorname{HBF}\left(r=-0.674, p=0.016, r^{2}=\right. \\
45.4 \%)\end{array}$ \\
\hline
\end{tabular}



Dos'Santos et
al. (16)
21 professional rugby and 19 collegiate athletes) $(23.0 \pm 2.9$
years; $88.05 \pm 12.86 \mathrm{~kg} \cdot 1.82 \pm$ $0.07 \mathrm{~m})$
Nedergaard et
10 male soccer players $(21 \pm 3$
years; $73 \pm 6 \mathrm{~kg} ; 1.78 \pm 0.1 \mathrm{~m})$
al. (62)
PP V cut $135^{\circ}$

Greig (21)

10 male professional soccer players
$(24.7 \pm 4.4$ years; $77.1 \pm 8.3 \mathrm{~kg}:)$

Kimura \&

Seven male university basketball $(19.4 \pm 0.7$ years; $; .80 \pm 0.07 \mathrm{~m}$,
$77.1 \pm 8.3 \mathrm{~kg}:)$

PP $180^{\circ}$ COD $3.5 \mathrm{~m}$ approach

Sakurai (45)

PP $60^{\circ}$ cut $5.83 \pm 0.32$

$\mathrm{m} \cdot \mathrm{s}^{-1}$

PP 505
Mod505 left: PFC peak HBF $\left(r=-0.337, r^{2}=\right.$ $0.114, p<0.05)$ HBF ratio $\left(r=0.429, r^{2}=0.184\right.$ $p<0.05)$

Fast vs slow (Mod505 left)

HBF ratio $(p=0.006, \mathrm{ES}=-1.50), \uparrow \mathrm{PFC} \mathrm{HBF}$ $(p=0.027, \mathrm{ES}=1.08)$
- $\uparrow$ average trunk decelerations in IPS and PFC vs FFC

- $\quad$ PFC vs FFC: $\uparrow$ peak joint angular velocities in knee and ankle

- $\quad$ GCT $\uparrow$ from IPS foot contact to PFC to FFC

PFC vs FFC: $\uparrow$ max knee flexion angle and ROM

PFC vs FFC: $\downarrow$ GCT $\uparrow$ posterior impulse
Stronger vs weaker (ECC knee extensor - (3.80 \pm 0.39 vs $2.93 \pm 0.24 \mathrm{Nm} \cdot \mathrm{kg}^{-1}$, $\left.\mathrm{ES}=2.69\right)$

- $\downarrow$ completion times $(p<0.0001, \mathrm{ES}=2.09)$ $\uparrow$ approach greater velocity ( $p=0.015$, ES $=1.27)$, $\uparrow$ reductions in velocity during the PFC (ES =-0.94)

- $\uparrow$ peak HGRF, average HGRF, hip flexo moments ( $\mathrm{ES}=0.95-1.23$ )

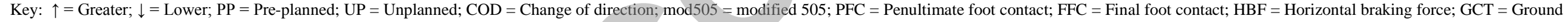

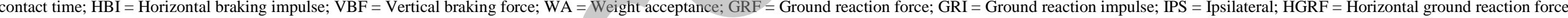
ECC = Eccentric; $\mathrm{ROM}=$ Range of motion; IPS = Ipsilateral foot contact; $\mathrm{pKAM}=$ peak Knee abduction moment; ES = Effect size

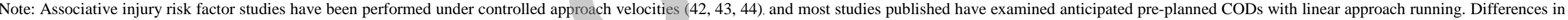

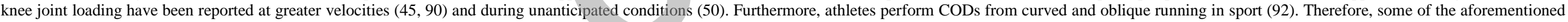

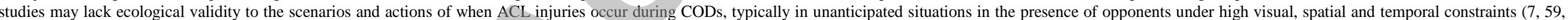




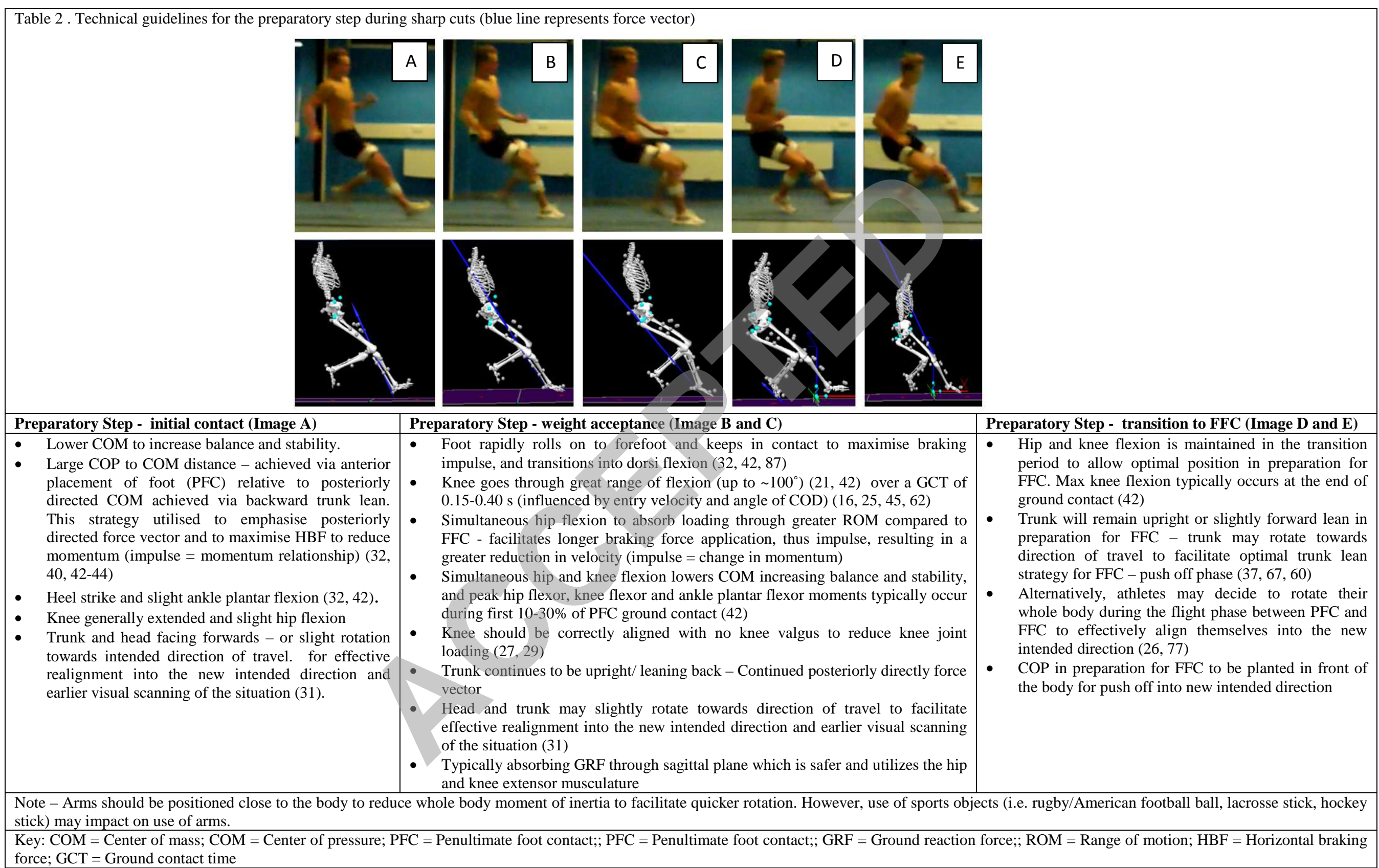




\begin{tabular}{|c|c|c|c|c|c|}
\hline Week & COD Emphasis & Drills & $\begin{array}{c}\text { Intensity } \\
\text { (perceived } \\
\text { speed) }\end{array}$ & $\begin{array}{c}\text { Total } \\
\text { Distance } \\
\text { (m) }\end{array}$ & $\begin{array}{l}\text { Number of } \\
\text { Decelerations } \\
\text { and CODs }\end{array}$ \\
\hline Week 1 & \multirow{2}{*}{$\begin{array}{l}\text { - } \begin{array}{l}\text { Drills specific to } \\
\text { deceleration } \\
\text { phase, before } \\
\text { adding turn and } \\
\text { reacceleration }\end{array} \\
\text { - } \quad \begin{array}{l}\text { Submaximal/ } \\
\text { pre-planned } \\
\text { emphasising key } \\
\text { aspects of } \\
\text { technique }\end{array} \\
\text { Progressive } \\
\text { increase in COD } \\
\text { angle and } \\
\text { approach } \\
\text { velocity }\end{array}$} & $\begin{array}{ll}\text { 1. } & 8 \times 5 \mathrm{~m} \text { acceleration to deceleration } \\
2 . & 6 \times 5 \mathrm{~m} \text { lateral shuffle to deceleration } \\
\text { 3. } & 6 \times 5 \mathrm{~m} \text { acceleration to side steps }\left(20-60^{\circ}\right)-5 \mathrm{~m} \text { exit } \\
\text { to deceleration } \\
\text { 4. } 6 \times 5 \mathrm{~m} \text { acceleration to turns }\left(135^{\circ}\right)-5 \mathrm{~m} \text { exit to } \\
\text { deceleration }\end{array}$ & $50-75 \%$ & 190 & 26 and 12 \\
\hline Week 2 & & $\begin{array}{l}\text { 1. } 8 \times 5 \mathrm{~m} \text { acceleration to deceleration } \\
\text { 2. } 6 \times 5 \mathrm{~m} \text { lateral shuffle to deceleration } \\
\text { 3. } 8 \times 5 \mathrm{~m} \text { acceleration to side steps }\left(45-90^{\circ}\right)-5 \mathrm{~m} \text { exit } \\
\text { to deceleration } \\
\text { 4. } 8 \times 5 \mathrm{~m} \text { acceleration to turns- } 5 \mathrm{~m} \text { exit to } \\
\text { deceleration }\end{array}$ & $75 \%+$ & & nd 16 \\
\hline Week 3 & \multirow{2}{*}{$\begin{array}{ll}- & \begin{array}{l}\text { Pre-planned drill } \\
\text { performed } \\
\text { maximally }\end{array} \\
\text { - } & \begin{array}{l}\text { Introduction of } \\
\text { unanticipated } \\
\text { generic stimuli } \\
\text { (auditory or } \\
\text { visual) }\end{array} \\
\text { - } & \begin{array}{l}\text { Unanticipated } \\
\text { performed } \\
\text { submaximally }\end{array}\end{array}$} & 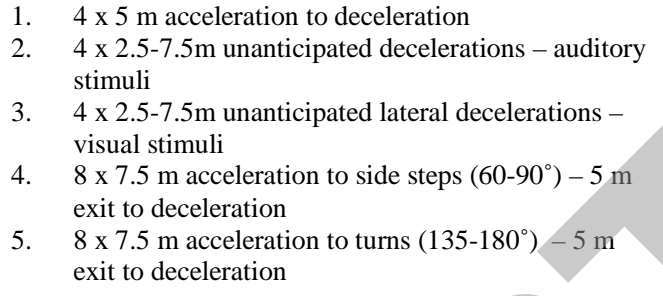 & 1. $100 \%$ & 240 & $\begin{array}{c}28 \text { and } \\
16\end{array}$ \\
\hline Week 4 & & $\begin{array}{l}\text { 1. } 6 \times 10 \mathrm{~m} \text { acceleration to side steps }\left(60-90^{\circ}\right)-5 \mathrm{~m} \\
\text { exit to deceleration } \\
\text { 2. } 6 \times 2.5-12.5 \mathrm{~m} \text { unanticipated decelerations - } \\
\text { auditory stimuli } \\
\text { 3. } 6 \times 10 \mathrm{~m} \text { acceleration to turns }\left(135-180^{\circ}\right)-5 \mathrm{~m} \text { exit } \\
\text { to deceleration } \\
\text { 4. } 6 \text { x unanticipated } 5 \mathrm{~m} \text { sidesteps }\left(45-90^{\circ}\right) \text { - coach } \\
\text { pointing }-5 \mathrm{~m} \text { exit } \\
\text { 5. } 6 \times \text { unanticipated clock face drill }(5 \mathrm{~m} \text { entry and } 5 \mathrm{~m} \\
\text { exit) - auditory stimuli (coach shouts number } \\
\text { corresponding to clock face }) \text { - decelerations and } \\
\text { CODs of any angle }\end{array}$ & $\begin{array}{l}\text { 1. } 100 \% \\
\text { 2. } 75 \%+ \\
\text { 3. } 100 \% \\
\text { 4. } 75 \%+ \\
\text { 5. } 75 \%+\end{array}$ & 315-375 & 24 and 24 \\
\hline Week 5 & $\begin{array}{ll}- & \begin{array}{l}\text { Unanticipated } \\
\text { drills performed } \\
\text { maximally }\end{array} \\
& \begin{array}{l}\text { Introduction of } \\
\text { sport specific } \\
\text { stimuli - } \\
\text { opponent or ball }\end{array} \\
\end{array}$ & $\begin{array}{l}\text { 1. } 8 \times 2.5-15 \mathrm{~m} \text { unanticipated decelerations - against } \\
\text { an opponent* } \\
\text { 2. } 8 \times 5 \mathrm{~m} \text { unanticipated cuts }\left(60-90^{\circ}\right)^{*} \text { - against an } \\
\text { opponent or ball - } 5 \mathrm{~m} \text { exit to deceleration } \\
8 \times 2.5-10 \mathrm{~m} \text { lateral shuffle mirror drill against an } \\
\text { opponent* } \\
4 . \quad \text { Modified } \mathrm{L} \text { runs }- \text { anticipated }-(5 \mathrm{~m} \text { acceleration } \\
\text { to } 90^{\circ} \text { cut, } 5 \mathrm{~m} \text { acceleration to } 180^{\circ} \text { turn }-5 \mathrm{~m} \\
\text { acceleration to } 90^{\circ} \text { cut to } 5 \mathrm{~m} \text { exit to deceleration. (3 } \\
\text { CODs and } 1 \text { deceleration per rep }=20 \mathrm{~m} \text { per rep) }\end{array}$ & $100 \%$ & $200-360$ & 20 and 28 \\
\hline Week 6 & & $\begin{array}{l}\text { 1. } 8 \times 2.5-155 \mathrm{~m} \text { unanticipated } 180^{\circ} \text { turn -against an } \\
\text { opponent* to deceleration } \\
\text { 2. } 8 \times 10 \mathrm{~m} \text { unanticipated COD - reacting to ball (60- } \\
\left.180^{\circ}\right)-5 \mathrm{~m} \text { exit to deceleration } \\
\text { 3. } 8 \times 2.5-10 \mathrm{~m} \text { lateral shuffle mirror drill - against an } \\
\text { opponent* } \\
\text { 4. } 4 \text { Modified L runs - anticipated - }(7.5 \mathrm{~m} \\
\text { acceleration to } 90^{\circ} \text { cut, } 7.5 \mathrm{~m} \text { acceleration to } 180^{\circ} \\
\text { turn }-7.5 \mathrm{~m} \text { acceleration to } 90^{\circ} \text { cut }-7.5 \mathrm{~m} \text { exit to } \\
\text { deceleration. (3 CODs and } 1 \text { deceleration per rep = } \\
30 \mathrm{~m} \text { per rep) }\end{array}$ & $100 \%$ & $280-460$ & 20 and 36 \\
\hline $\begin{array}{c}\text { Additiona } \\
1 . \\
2 . \\
3 . \\
\text { Key: } *=A\end{array}$ & $\begin{array}{l}\text { formation: } \\
\text {-60 seconds' rest provid } \\
1 \text { CODs and deceleration } \\
\text { edback to be provided to } \\
\text { ernate between leading a }\end{array}$ & $\begin{array}{l}\text { etween } 100 \% \text { effort reps. } 2 \text { minutes' rest provide betweer } \\
\text { be performed with the aim of modified braking strategy } \\
\text { ch player after each rep regarding braking strategy/ COD } \\
\text { eacting / attacking and defending; COD = Change of dire }\end{array}$ & $\begin{array}{l}\text { cises } \\
\text { ique } \\
\text { PFC }=\end{array}$ & & \\
\hline
\end{tabular}




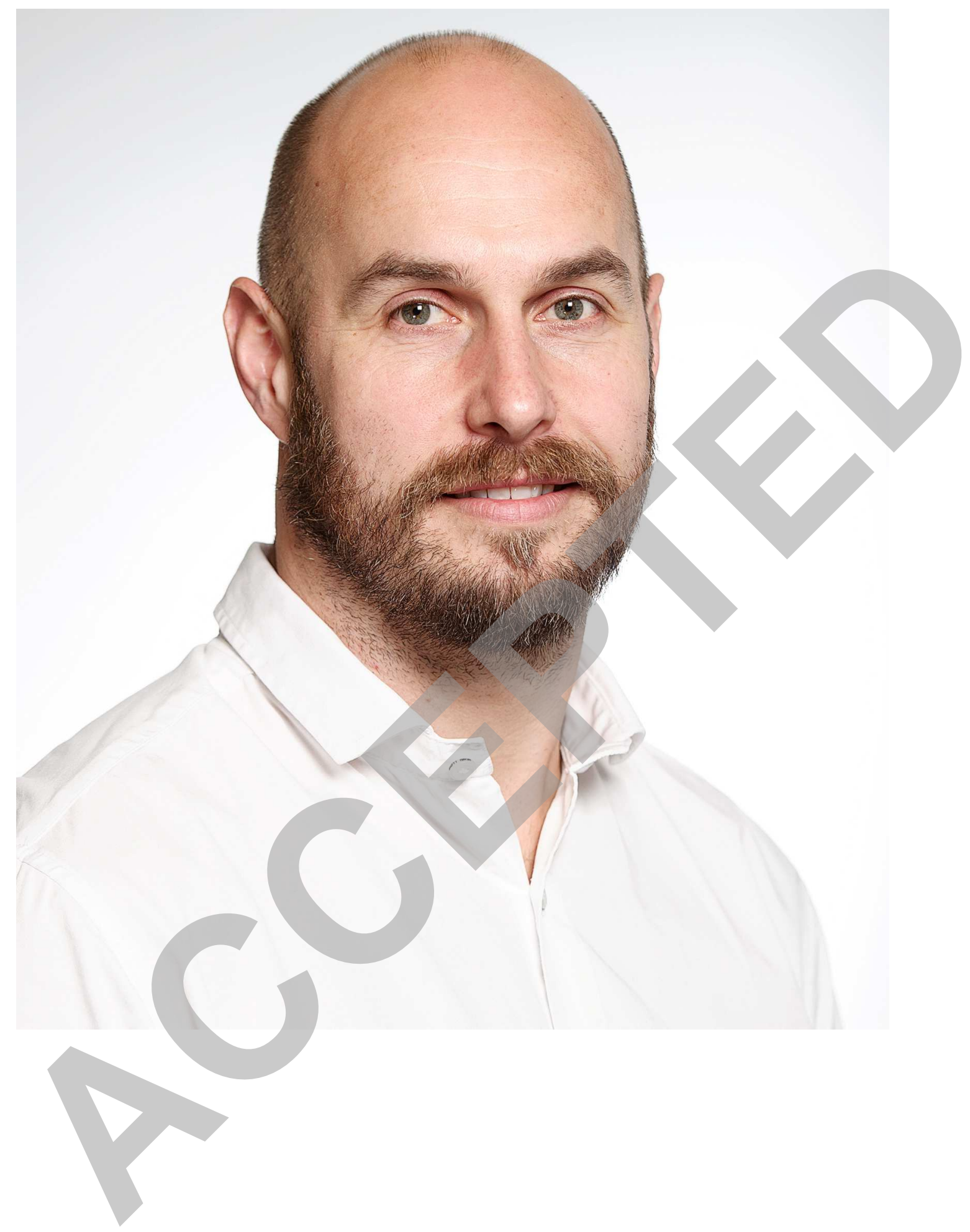

Copyright (c) 2018 Wolters Kluwer Health, Inc. Unauthorized reproduction of this article is prohibited. 


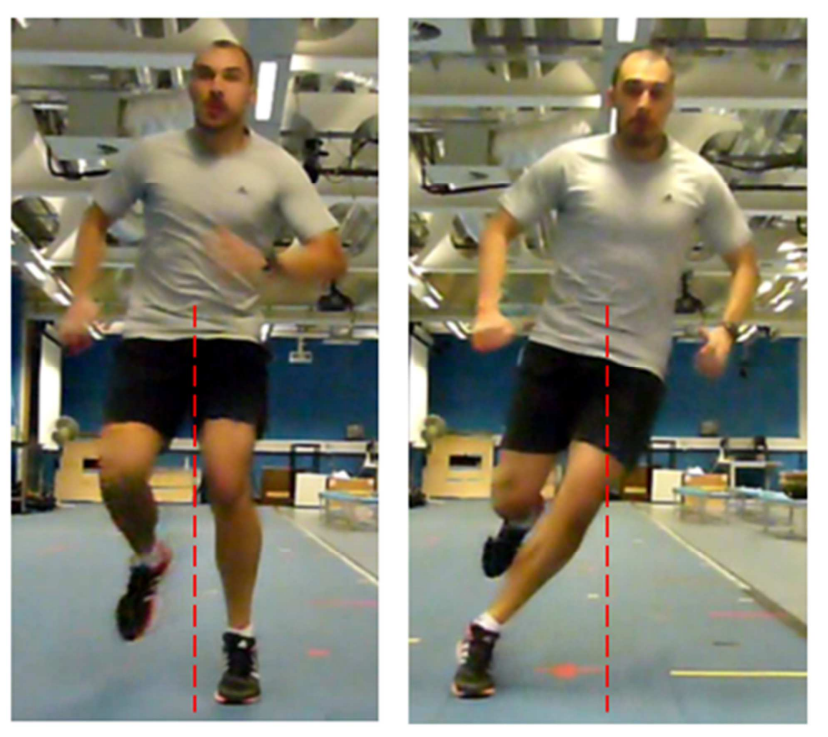

Copyright (c) 2018 Wolters Kluwer Health, Inc. Unauthorized reproduction of this article is prohibited. 


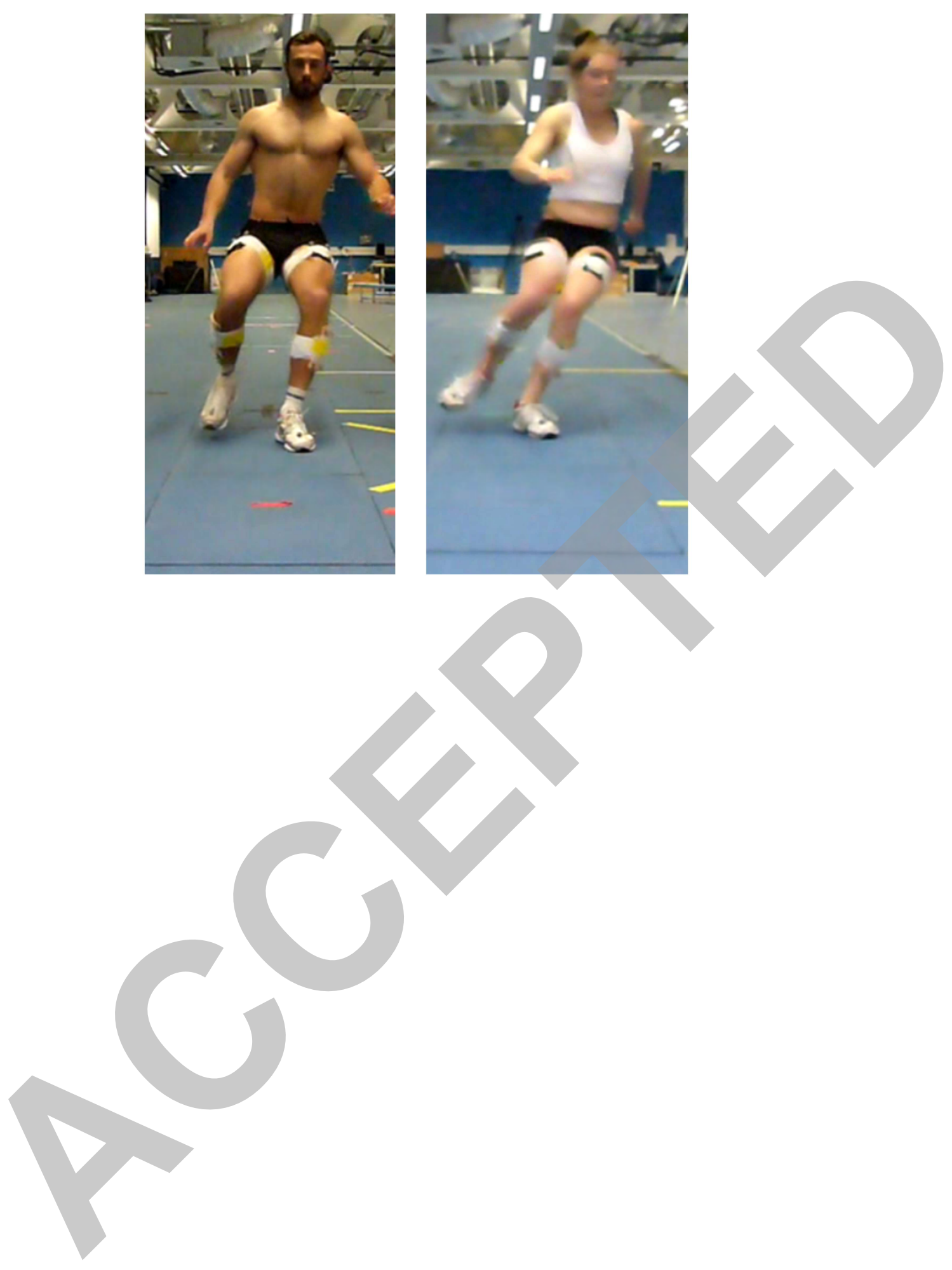



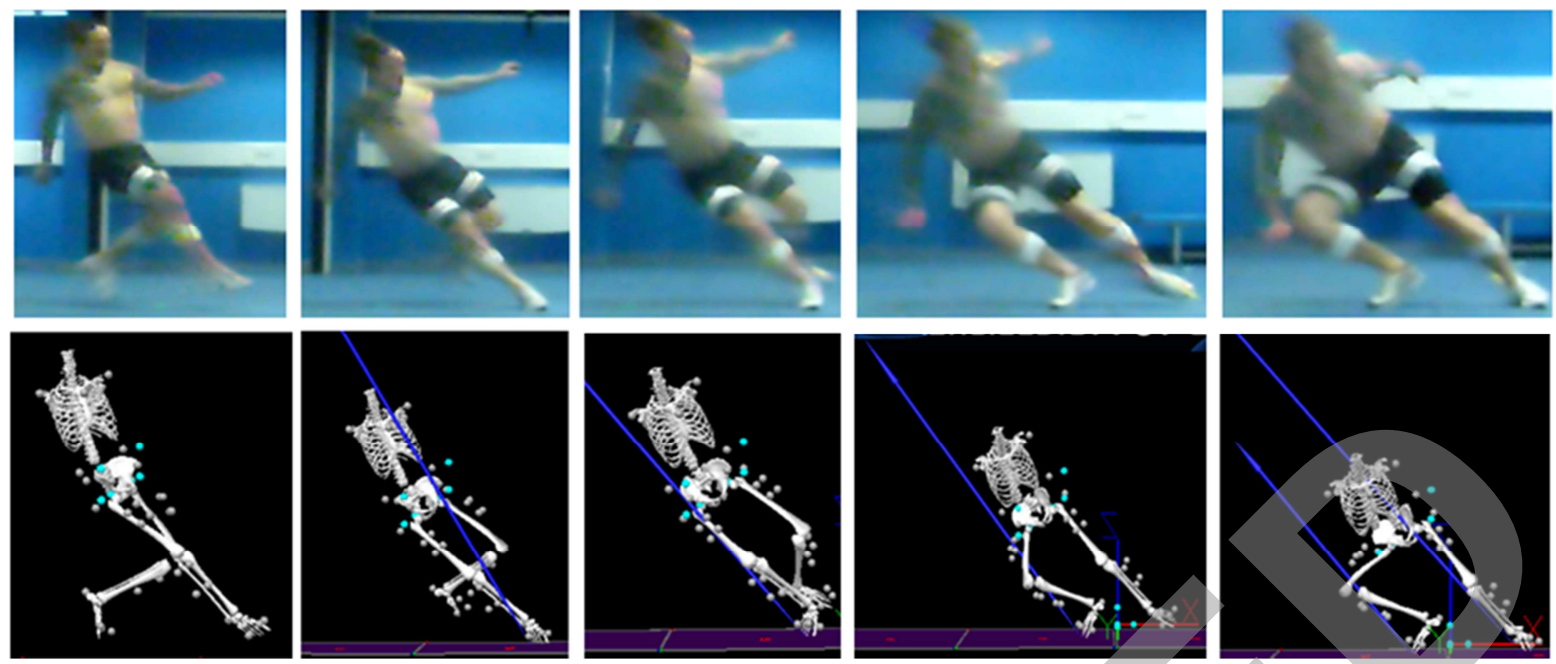

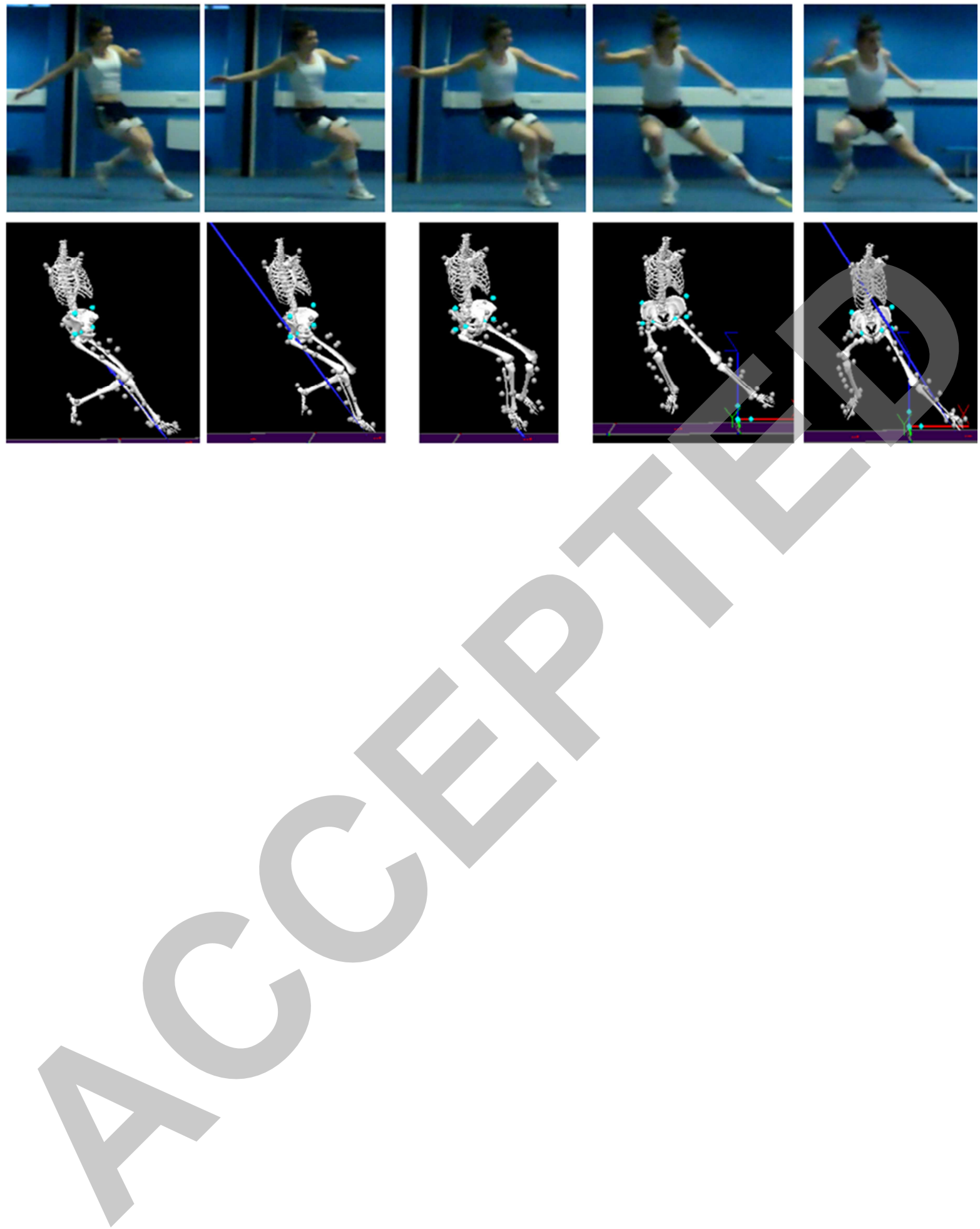


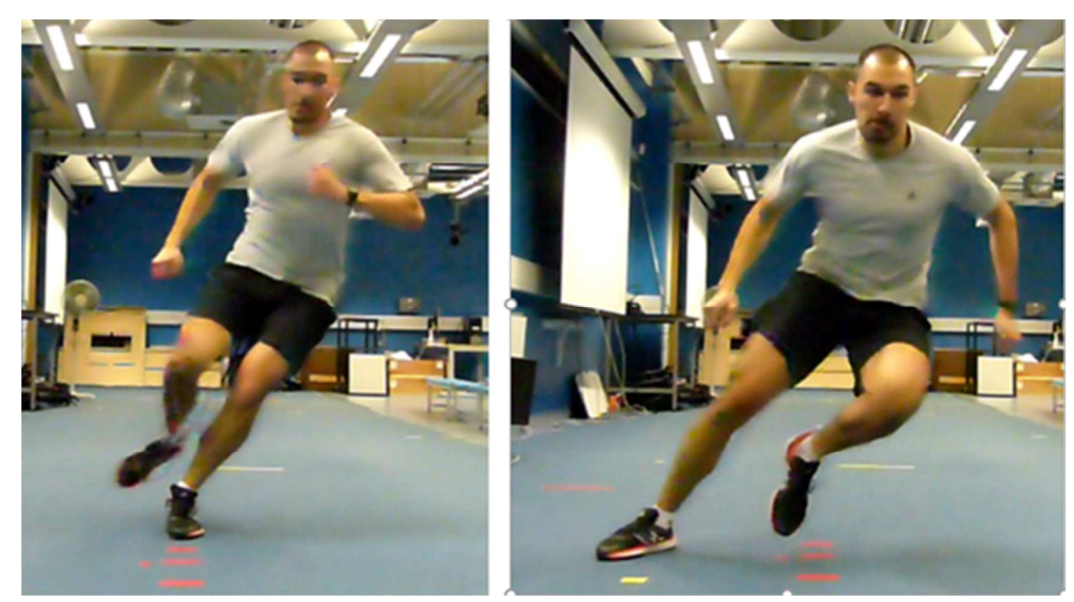



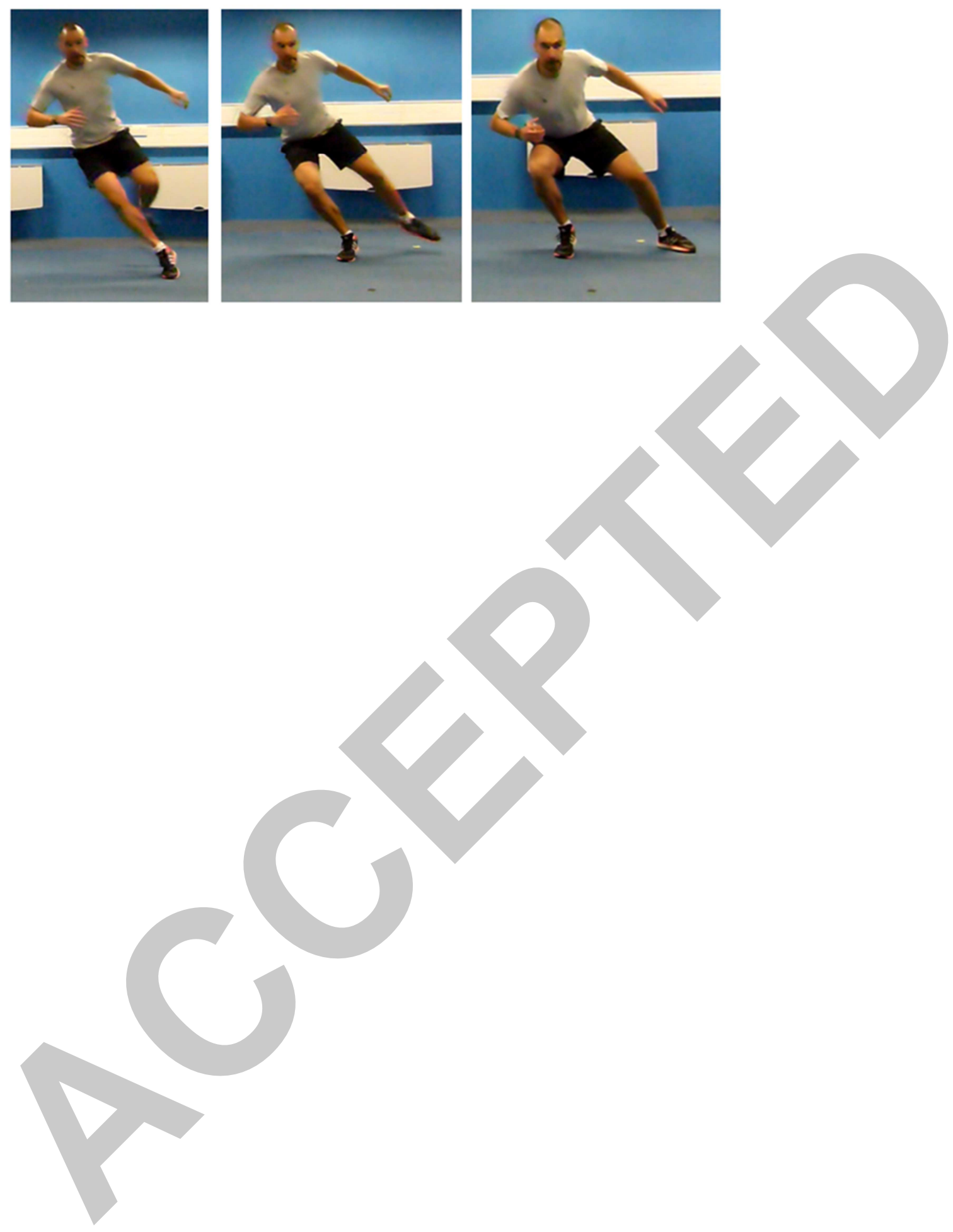


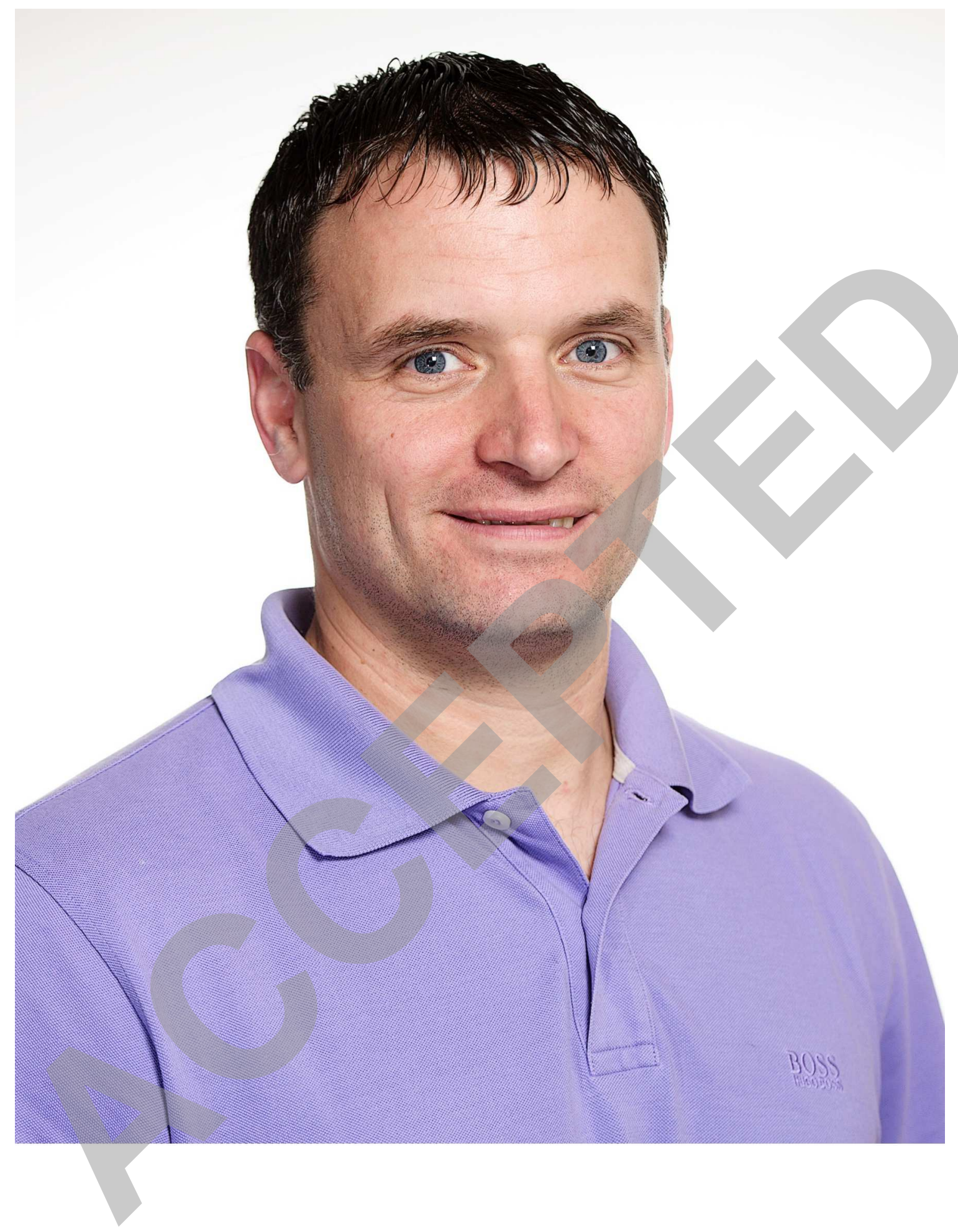

Copyright (c) 2018 Wolters Kluwer Health, Inc. Unauthorized reproduction of this article is prohibited. 

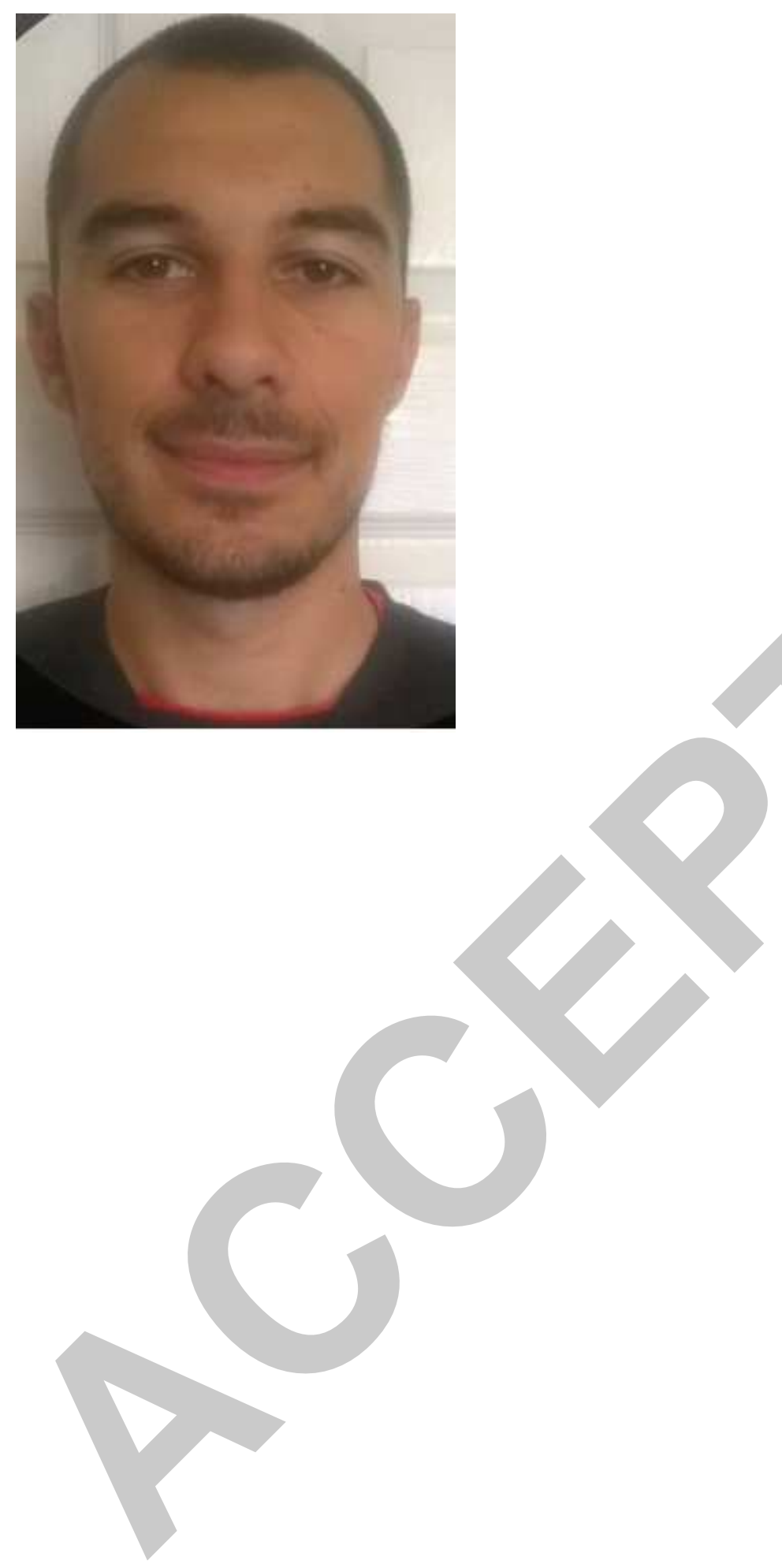

Copyright (c) 2018 Wolters Kluwer Health, Inc. Unauthorized reproduction of this article is prohibited. 

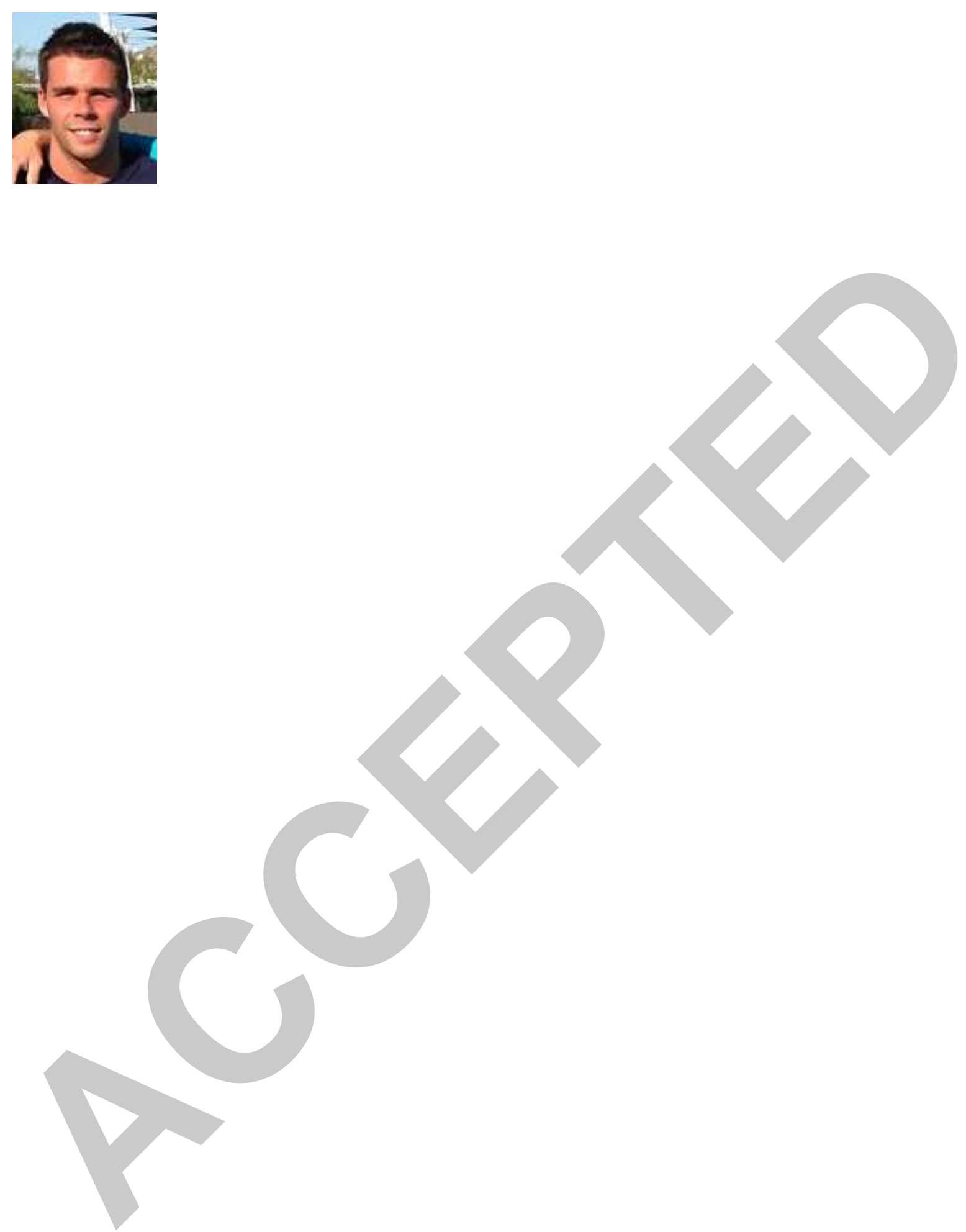